\title{
CULTURA, SENTIDO E POLÍTICA
}

Ramón Máiz

Universidade de Santiago de Compostela

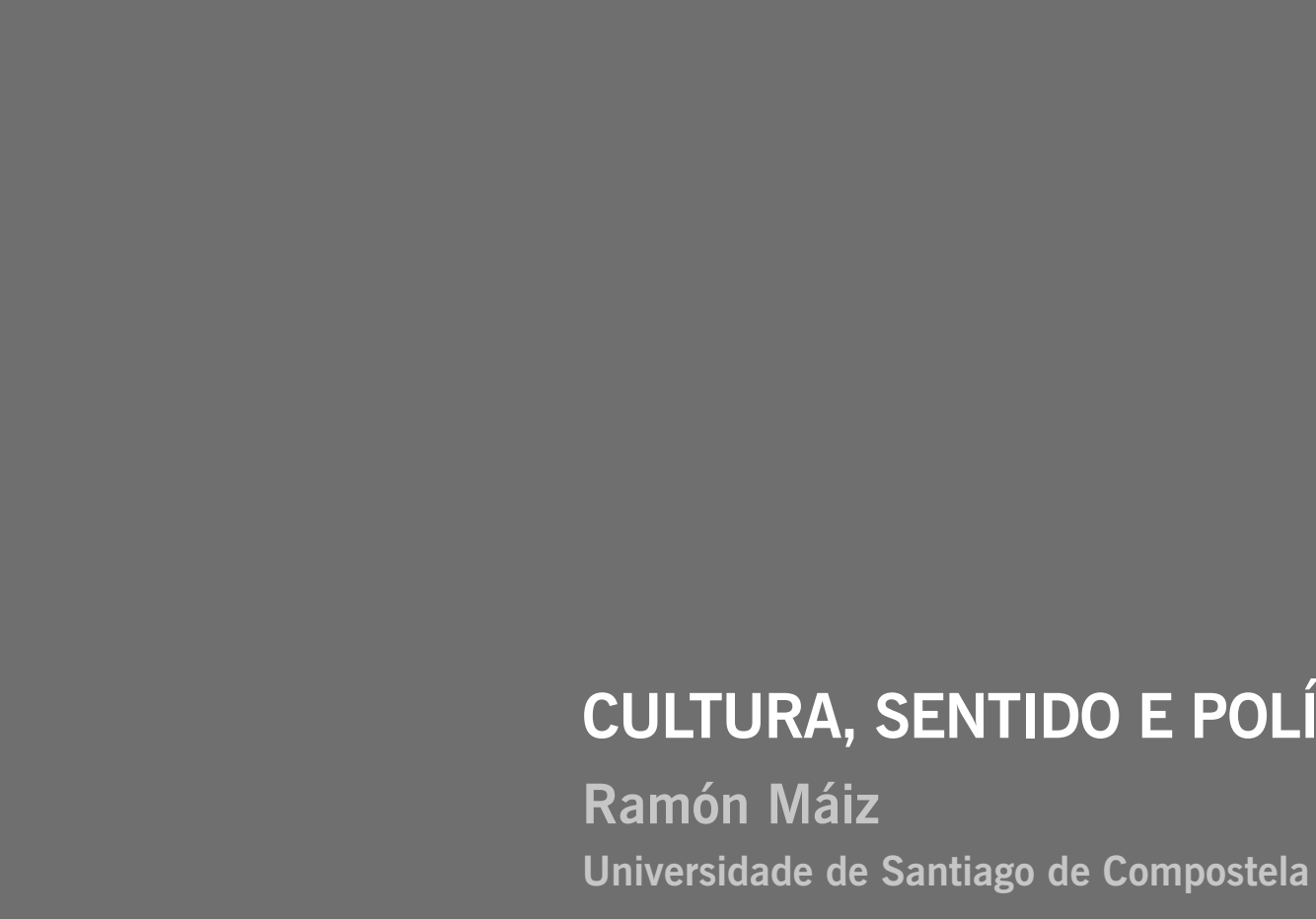



Culture is always composed of seriously contested codes and representations. James Clifford, Writing Culture

If the word "culture" is a historical and philosophical text, it is also the site of a political conflict [...]. [C]ulture arises when civilization begins to seem self-contradictory. Terry Eagleton, The Idea of Culture

O concepto dominante de cultura na ciencia política contemporánea —o concepto de «cultura política»— resultou debedor, como é ben sabido, da revolución behaviorista dos anos sesenta, e serviu durante moito tempo para designar o conxunto de actitudes e valores que producían pautas de orientación cara ao sistema político («orientations to the political system» [Almond e Verba 1963]). Diversas investigacións posteriores proseguiron con este específico obxecto de estudo (Almond e Powell 1966; Verba, Nie e Kim 1978; Inglehart 1990, 1997; Inglehart e Norris 2018), que implicaba un moi reducionista concepto de «cultura», caracterizado pola exclusiva atención a «the pattern on individual attitudes and orientations towards politics among members of a political system», isto é, á cultura considerada como mero agregado de disposicións, actitudes e valores individuais. Esta liña dominante de investigación, por unha banda, bloqueaba por definición a análise da dimensión intersubxectiva da produción de sentido político (Ross 2009) e, pola outra, ofrecía unha guía menos rigorosa para a investigación empírica da política ca outros conceptos como o de interese, que o ascenso da rational choice situaría cada vez máis no primeiro plano (Przeworsky 1985).

Por outra parte, a necesidade crecente de dar conta da dimensión colectiva de determinados fenómenos sociais e políticos, como os conflitos relixiosos, ét- 
nicos ou nacionalistas, conduciría á recepción na ciencia política dun concepto en exceso holístico de cultura, «civilización» (Huntington 1996) ou «identidade cultural» (Huntington 2004), que sublińaba os trazos primordiais compartidos (relixión, lingua), a socialización pasiva na comunidade e o inevitable conflito entre os pobos e as civilizacións. Nos anos setenta, o éxito da obra de Clifford Geertz The Interpretation of Cultures contribuíu a fornecer unha definición de cultura como "web of significance», como «a historically transmitted pattern of meaning embodied in symbols» (Geertz 1973) que, ao tempo que chamaba a atención sobre a capital dimensión simbólica dos grupos e as sociedades, insistía quizais en exceso nos aspectos comunitarios, compartidos, dela, e puña á marxe o pluralismo e o conflito internos consubstanciais a toda cultura (Wedeen 2002). As diverxencias entre ambas as correntes evidénciaa a obra de King, Keohane e Verba Designing Social Inquiry, na que, precisamente, a obra de Geertz se toma como referencia para a crítica do interpretativismo nas ciencias sociais, ao tempo que non se elabora un novo concepto de cultura política que atenda á produción política da significación alén das orientacións individuais, cunha patente obsesión unilateral polos procedementos inferenciais de investigación (King, Keohane e Verba 1994: 38-40).

Pois ben, esta tensión entre os dous extremos precitados de individualismo e comunitarismo posúe unha longa tradición tamén na teoría política. Tamén aquí atopamos quer un exceso de individualismo que desatende os aspectos da intersubxectividade e a comunicación nos fenómenos culturais, quer un exceso de holismo que reforza os lazos comunitarios, esaxera as diferenzas nós/eles e minimiza as dimensións de conflito interno, dinamismo e mudanza presentes en toda cultura. A réplica comunitarista, nas súas diferentes versións (McIntyre, Sandel ou Taylor), ao individualismo liberal de Rawls constituíu o locus classicus da necesaria atención aos shared understandings. Mais, nunha especie de movemento pendular, isto conduciu, en numerosas ocasións, a un concepto de cultura en exceso esencialista e primordialista, que resaltaba de máis a homoxeneidade dos grupos étnicos, as comunidades ou as nacións.

Nas liñas que seguen propońémonos analizar: 1) algúns dos principais argumentos e conceptos desta tensión individualismo/holismo herdados (e aínda vixentes) de dúas conxunturas críticas na historia do pensamento (a crítica romántica da Ilustración e a crítica posmoderna da idea de vangarda cultural), e 
2) a reformulación do concepto de cultura que tivo (ou está a ter) lugar, máis recentemente, na crise teórica e política do primeiro multiculturalismo e do nacionalismo cultural, e o paralelo xurdimento dunha idea de cultura como práctica semiótica, allea ao paradigma clásico, nas ciencias sociais e, en concreto, na ciencia política contemporánea.

Abofé, a teoría e as políticas do multiculturalismo e do nacionalismo cultural resultan debedoras, por unha banda, das mudanzas sociais e políticas derivadas da globalización, das reclamacións e as mobilizacións arredor do pluralismo cultural (plurinacionalismo, emigración, formas de vida alternativas) como fenómeno emerxente no mundo contemporáneo. Todo isto en desafío á homoxeneidade cultural (a tradicional ecuación Estado = nación = cultura) dos Estados nacionais, ás teses banais de «aquí fanse as cousas así» ou «somos máis e estabamos aquí antes de chegaren vostedes». Mais, por outra banda, o multiculturalismo e o nacionalismo cultural posúen a súa propia xenealoxía cultural, as súas raiceiras ideolóxicas e filosóficas, patentes na radical reformulación do concepto de cultura que postulan: a súa estrutura, historia, dimensións, relevancia etc. $\mathrm{O}$ argumento que propoñemos sostén que o concepto de cultura propio do multiculturalismo e do nacionalismo culturalista resulta debedor intelectual de, polo menos, dous movementos chave no eido das humanidades e das ciencias sociais. Estes dous desprazamentos son os seguintes: 1) a crítica romántica ao concepto universalista e "progresista» da civilización propio da Ilustración, e 2) a crítica posmoderna ás ideas de estilo e arte de vangarda propias da modernidade.

Este duplo desprazamento resulta capital, non suficiente, mais indispensable para entender o alcance, a relevancia e a textura do concepto contemporáneo de cultura que subxace aos debates referidos ás políticas do nacionalismo liberal e o multiculturalismo, o cal desborda amplamente, nas súas implicacións sociais e políticas, un suposto "xiro culturalista» e despolitizador da teoría política, os deseños institucionais e as políticas públicas. E, así mesmo, esta dupla débeda para co Romanticismo e o posmodernismo devén decisiva para explicar o tránsito teórico-práctico, profundamente autocrítico, desde unha inicial versión comunitarista e holista do multiculturalismo e o nacionalismo cara á versión construtivista e pluralista que caracteriza moitas das máis recentes formulacións de ambos os conceptos. Por último, nas ciencias sociais, un amortecido impacto teórico do posmodernismo (Wedeen 1999, 2002, 2008; Ross 2009), por unha banda, e, 
sobre todo, o desenvolvemento de programas de investigación da etnicidade e os nacionalismos, construtivistas e relacionais (Hale 2008, Chandra 2012), por outra, serán, entre outros, os factores que expliquen a aparición do concepto de cultura como conxunto plural de prácticas semióticas, converxente co desenvolvido polo nacionalismo cultural e o multiculturalismo intercultural (Laitin 2007: IX).

\section{AS RAÍCES DO DEBATE: «CULTURA» VS. «CIVILIZACIÓN» NA CRÍ- TICA ROMÁNTICA DA ILUSTRACIÓN}

O Romanticismo constituíu, como é sabido, unha crítica radical da modernidade, mais non debe esquecerse, con todo, que se tratou case sempre de «une critique moderne de la modernité» (Löwy e Sayre 1992: 35). O pensamento moderno radicalizouse na primeira Ilustración construíndo unha imaxe do mundo e da vida — da man da metáfora da luz (lumières, Aufklärung, enlightment, luces, illuminismo) — a partir dunha idea de Razón entendida especificamente como racionalidade científico-matemática. As consecuencias disto resultan ben coñecidas: separación entre suxeito (cognoscente) e obxecto (cońecido), matematización da experiencia (raciocinatio est computatio), tecnificación do método e, en fin, secularización e desencantamento do mundo (Entzäuberung en Max Weber).

Ora ben, a radicalización técnico-científica do pensamento de Bacon, Newton e Descartes comportou non só unha filosofía antropocéntrica e de dominio e explotación da natureza, considerada esta última como mero recurso instrumental, dispoñible e ilimitado, senón tamén unha idea de civilización universal, da man da ciencia e da técnica, que se impuña de modo crecente como lei inexorable do progreso á pluralidade de culturas existentes, as cales resultaban, así, entendidas como os residuos do atraso social, atávicas barreiras particularistas á converxencia final do destino común da humanidade. Narcisismo de distancia respecto á natureza (res cogitans vs. res extensa), que se reforza, alén disto, nunha idea de liberdade entendida non só como autonomía — sapere aude—, senón como distanciamento e fractura do individuo con relación á súa base comunitaria, aos seus lazos sociais, en radical desarraigamento respecto á cultura herdada e ás súas institucións, costumes e crenzas. Só desde unha filosofía materialista, 
desde unha razón calculadora e universalista ( vid. cadro 1), pode entenderse a simultánea e articulada postulación tanto de 1) un ser humano considerado como individuo asocial descontextualizado (unencumbered self), e 2) o preceptivo abandono do estado de natureza comunitario e o artificio do contrato social fundador do Estado, canto de 3) a imaxinaría mecanicista da teoría social e política moderna (non só a natureza, senón tamén a política mesma entendida «ad instar Horologii» en Leibniz, «sicut enim in Horologio automato aliave machina» en Hobbes, culminan na concepción «comme une machine ordinaire, avec ses rouages» en Sieyès).

Nada disto, porén, é pasado, mera historia do pensamento. Podemos rastrexar contemporaneamente os ecos desta filosofía ilustrada na obra fundacional de Rawls e a súa articulación analítica dos conceptos debedores do racionalismo individualista lockeano: razoabilidade/racionalidade, autonomía, consenso e prioridade do xusto sobre a idea de ben, teoría dos incentivos etc. Aquí postúlase, en efecto, un redutivo desdobramento do concepto de razón en racionalidade (a procura dos propios intereses e ideas de ben) e razoabilidade (a capacidade de chegar a acordos cooperativos para fundamentar as institucións democráticas). Por unha banda, mediante o exercicio da racionalidade individual (autonomía moral) prodúcese o pluralismo inconmensurable de ideas de ben, de doutrinas comprehensivas, de ideas de ben ou vida boa. Pola outra, mediante a razoabilidade (autonomía política) xérase, da man da hipótese neocontractualista da «posición orixinal», un consenso superposto (compatible desde diversas ideas de ben) que aluma os principios de xustiza que deben presidir as institucións políticas. Para os efectos da nosa argumentación, hai dúas teses rawlsianas que deveñen decisivas: 1) a tese da prioridade da xustiza sobre o ben (a diferenza do utilitarismo) e 2) a tese de que as ideas de ben, quer individuais, quer compartidas, non pertencen á razón pública (a diferenza do comunitarismo), senón que constitúen usos non públicos da razón que deben ficar no ámbito da máis estrita intimidade. Todo isto tradúcese en que as «devocións e os afectos» [sic], vencellados aos «vínculos e lealdades» particulares, os contextos culturais e de sentido, propios das ideas compartidas de ben, han quedar fóra do overlapping consensus que aluma os principios abstractos de Xustiza. Isto é, as paixóns e emocións conectadas ás ideas de ben, propias das comunidades e as culturas que dotan de raíces e sentido a vida dos seres humanos, incluídas "as conviccións e paixóns da maioría» [sic], 
deben ficar excluídas (nos seus propios termos: «not taken into account») do eido, racional por definición, da política.

Pois ben, a crítica romántica e posromántica ao modelo ilustrado pouco ten que ver co mero irracionalismo, coa elemental procura de «ruiner la théorie rationaliste de l'État» (Droz 1966: 44) da man dun suposto desprezo á Razón ao que «aucune des doctrines irrationalistes de son temps ne lui a donc été étrangère» (Droz 1966: 48). Nin pode ser reducida ao comunitarismo conservador dun Scruton ou un McIntyre (Taylor 1989). O obxectivo prioritario dos románticos era, sobre todo, ao fío da primeira crise da modernidade, a interrogación sobre a linearidade do Progreso e o seu custo humano, social e cultural (explotación capitalista, terror revolucionario, destrución da natureza) e a reintrodución da complexidade coa relativización, que non supresión, das dicotomías radicais da Ilustración: suxeito/obxecto, feito/valor, res cogitans/res extensa, razón/emoción, mediante a recuperación da súa, por dicilo en termos do último Kant, «descoñecida raiceira común».

Esta crítica moderna da modernidade apunta, desde a metáfora da Noite, a determinados excesos, e só a eles e non ao conxunto do paradigma, da Ilustración primeira —que ela mesma parcialmente autocorrixiría, como pode comprobarse na Crítica do xuizo de I. Kant-. En concreto (Abrams 1971, Löwy e Sayre 1992, Berlin 1999, Larmore 1996, Chai 2006): 1) o desencantamento do mundo, para lle devolver a súa dimensión perdida de misterio, de conciencia dos límites e da finitude; 2) a cuantificación do mundo e o dominio «filisteo» (Marx) dos intereses materiais, para recuperar o lugar dos valores, os principios e as virtudes cívicas; 3) a interpretación mecanicista da sociedade e a natureza, para lle opor unha visión organicista, evolucionista e adaptativa; 4) a abstracción universalista da Civilización, para recuperar o valor do heteroxéneo e plural contexto cultural e lingüístico da humanidade; 5) o hiperracionalismo frío e desapaixonado, centrado obsesivamente no interese, para reivindicar o valor ético-político e cultural dos afectos e as emocións, e 6) a perda de raíces culturais comúns da man dun individualismo exacerbado, para reclamar a esquecida eticidade (Sittlichkeit) compartida (e tamén conflitiva, non se esqueza) e as bases sociais comunitarias provedoras de sentido.

Elementos fundamentais desta perspectiva romántica foron a revalorización simultánea e intimamente imbricada de 1) a natureza fronte ao artificio, e 2) as 
culturas e linguas comunitarias, fronte ao mito universalista e homoxeneizador do Progreso. Desta sorte, o mesmo movemento intelectual que reformulaba a utopía do progreso ilimitado (memento ascendere semper), desde a lúcida conciencia da finitude e os límites (tanto da razón humana como da natureza mesma), puña de relevo, por unha banda, a inserción do ser humano na natureza e a irredutibilidade desta última a mero cálculo instrumental, exterioridade estática e simple recurso que explotar, mediante unha visión orgánica, "ambientalista» e evolucionista dela. Por outra, procedíase á recontextualización do individuo no mundo de sentido (histórico, lingüístico, cultural, institucional) da comunidade e, deste xeito, á modulación da autonomía coa dimensión da autenticidade, ao recoñecemento da débeda para coa propia tradición e o mundo de sentido comunicativo e compartido en que habitamos.

Nada disto é, tampouco, cousa do pasado, mero prurito historiográfico: a moi influente obra de Charles Taylor testemuña a recepción destes argumentos no debate contemporáneo (Taylor 1989, 1992). Se Herder reclamaba unha comprensión interna das culturas, sempre no plural, xulgándoas inconmensurables, no canto de lles aplicar os principios a priori da Razón ou os estándares universais da Civilización, é porque estes últimos non eran, ao seu xuízo, nin absolutos nin universais, senón debedores dunha Cultura, a occidental, e o seu tempo específico, a modernidade; isto é: profundamente etnocéntricos (Beiser 1987: 143). Non foi tampouco a negación da razón e a ciencia o propio da conciencia romántica, senón a construción dun retrato da razón sensible, da inseparabilidade da razón e a emoción, e dunha ciencia orgánica, evolucionista, fronte á ciencia mecanicista, como a obra de Darwin amosaría de modo xenial (Richards 2002: 514).

Menos aínda a insistencia dos primeiros románticos no valor da comunidade e da pluralidade das culturas se realizou, como se dixo ata a saciedade, ao prezo de erosionar o valor da liberdade individual e a autorrealización. Nada hai neles de irracional defensa do prexuízo e da tradición (Burke, De Maistre): o recoñecemento do valor crítico da razón non lles impide, no entanto, coma ao optimismo ilustrado, ignorar o seu lado escuro, as súas consecuencias destrutivas, o mister Hyde que axexa tras os excesos cientistas do doutor Jekyll. De aí a reformulación, que non rexeitamento, da Bildung, a depuración do elitismo de Goethe e Humboldt, para valorar a riqueza das linguas e culturas populares e nacionais, así como a defensa da accesibilidade da formación para todos os cidadáns. A vi- 
sión orgánica da sociedade e as súas metáforas vexetais dos primeiros románticos ía dirixida contra o artificialismo, elitista e autoritario, do modelo mecanicista científico-técnico da Ilustración; a saber: 1) a diferenza das máquinas, que poden ser descompostas nas súas engrenaxes e mecanismos, os individuos non se relacionan entre si só movidos por un egoísmo autointeresado e solipsista, senón que están vencellados por un mundo compartido de sentido, crenzas e emocións; 2) a diferenza das máquinas, que requiren un axente externo que forneza a enerxía precisa para o seu funcionamento, a sociedade moderna non se ve abocada a estar gobernada por unha elite incontestable e a súa alta cultura, inaccesible ás masas populares obedientes; 3) a diferenza das máquinas, que precisan a forza física para o seu mantemento, a sociedade precisa non só coerción, senón unha cultura compartida (valores, crenzas, actitudes), sen a cal as institucións non se sosteñen no tempo, e 4) en fin, a diferenza das máquinas, que son o resultado dun deseño e dunha planificación racionais, a sociedade é o produto continxente de mudanzas culturais evolutivas e adaptativas a cada contexto e tempo específi$\cos$ (Beiser 1992).

Deste xeito prodúcese unha inversión do argumento ilustrado: a idea de Ben, de «vida boa», que reside nas institucións, tradicións, vocabularios e prácticas culturais da comunidade, vólvese prioritaria á idea de xustiza e os seus principios, os cales, pola súa vez, deveñen debedores dos valores e crenzas daquela. Ora ben, e isto resulta decisivo, a tradición romántica non debe lerse de xeito unilateral -a partir dos seus epígonos e da evolución conservadora do pensamento europeo posrevolucionario - como unha proposta de sutura comunitarista ou nacionalista de homoxeneidade axiolóxica, senón, pola contra, a partir do recońecemento tráxico do pluralismo e o conflito interno de valores, crenzas e principios no seo da comunidade (Berlin 1999: 32). Os románticos expresan as dislocacións sociais e os conflitos políticos resultado da Revolución Francesa e da primeira crise da Revolución Industrial: estaban «entregados á traxedia do seu tempo» (Williams 1960: 33). Pluralismo cultural e político que atinxe tanto á diversidade externa de formas de vida no mundo, e ao igual respecto (anticolonial) entre elas, canto ao pluralismo interno de interpretacións e procesos de creación e mudanza da propia cultura herdada. Non debe esquecerse que o Romanticismo foi o pensamento da escisión, da imposibilidade da fusión na natureza (ambigüidade do sublime: atracción e á vez espanto) ou na comunidade (consenso e disentimento, 
cooperación e conflito), e de aí o absurdo de toda quimérica socialización pasiva na tradición. Pola contra, o pluralismo e o conflito, a dimensión agonista, e xa que logo propiamente política de toda comunidade, nunca suturada nin reconciliada, senón en permanente reconstrución e debate, conduce a unha idea de cultura como creación irrestrita, como imaxinación produtiva, como proceso inacabado, máis ca como obxecto dado (Larmore 1966), como apertura, continxencia e indeterminación. Conciencia tráxica que remite a dimensión cultural á estofa mesma da política, non como mera expresión adxectiva de identidades comunitarias dadas, senón como proceso plural e conflitivo de creación colectiva e individual, de construción participativa desas culturas e identidades, xamais fixadas para sempre nunha síntese nin definitiva nin esencial.

\section{ILUSTRACIÓN}

\begin{tabular}{cc}
\hline Razón & Sensibilidade \\
\hline Secularización & Misterio \\
\hline Materialismo/Intereses & Paixóns \\
\hline Artificio/Contrato & Natureza \\
\hline Máquina/Técnica & Organismo/Vida \\
\hline Ciencia & Arte \\
\hline Universalismo & Particularismo \\
\hline Civilización & Cultura \\
\hline Individuo & Comunidade \\
\hline Progreso & Finitude, límites \\
\hline Pobo & Nación \\
\hline Lei/Xustiza & Ideas de ben \\
\hline Moralidade & Eticidade \\
\hline Autonomía & Autenticidade \\
\hline Consenso & Conflito \\
\hline Cosmopolitismo & Nacionalismos \\
\hline Colonialismo & Anticolonialismo \\
\hline
\end{tabular}

$\overline{\text { Cadro 1. Os campos semántico-conceptuais da idea de cultura na Ilustración e no Roman- }}$ ticismo. Fonte: elaboración propia

\section{ROMANTICISMO}




\section{O CONCEPTO «INTERTEXTUAL» DE CULTURA VS. VANGARDA NO POSMODERNISMO}

Temos que dar un longo salto no tempo para atendermos ao segundo desenvolvemento filosófico e artístico que incidirá dun xeito decisivo na reformulación do concepto de cultura que vai operar no multiculturalismo e no nacionalismo e, en menor medida, nas ciencias sociais: o movemento posmoderno. Hai trazos constitutivos do posmodernismo que, para os efectos que aquí interesan, non poden pasar desapercibidos:

1) A tese de que desde o punto de vista económico, cultural, sociolóxico e político se produciu unha transición da modernidade a un novo estadio históricocultural ou, incluso, alén da historia mesma (un eterno presente). O desenvolvemento cualitativo das tecnoloxías, os medios de comunicación, a informatización e as mudanzas na produción (traballo inmaterial, posfordismo) (Negri e Hardt 2000, 2004, 2009) deron á luz unha sociedade «postindustrial» e á vez «postradicional» (Giddens 1991) de "capitalismo tardío» (Jameson 1991). 2) O rexeitamento do modernismo artístico e das vangardas, postulando a liberalización da estética das servidumes da coherencia, a innovación e a funcionalidade. Situando a significación, a referencia intertextual e a autorreflexividade como valores autónomos, abandonando o elitismo e recuperando o valor perdido da cultura popular. 3) A radicalización das teses do postestruturalismo como impugnación da Razón centrada no suxeito soberano, as grandes narrativas, as pretensións universais de validez, a idea de totalidade e completude e, en xeral, da hiperracionalidade ilustrada clásica (Lyotard). 4) A crítica do fundacionalismo filosófico e teórico e a aposta por unha «nova superficialidade» que se enfronta ás esaxeradas pretensións de profundidade que tiranizan o pensamento moderno; a saber: o modelo hermenéutico «interior»/«exterior», o modelo dialéctico «esencia»/«aparencia», o modelo freudiano «latente»/«manifesto», o modelo existencialista «autenticidade»/«alienación» etc. E finalmente 5) a tese da diferenza entendida como articulación de prácticas sociais, políticas e culturais, e de narrativas e interpretacións locais, que se prolonga nun gusto indisimulado polas minorías nacionais, culturais, marxinais etc. así como polos «novos» movementos sociais e as novas prácticas políticas particularistas.

A partir destas características iniciais —e alén dos seus evidentes, innegables excesos na derrogación das pretensións de verdade ou no anything goes ético- 
-político-, o posmodernismo elabora criticamente polo menos cinco grandes temas do pensamento e a cultura modernos: o Suxeito, a Historia, a Teoría, a Política e a Cultura mesma, piares básicos que serán postos en causa nos termos en que veñen formulados ou, como mínimo, segundo a fórmula de Paul Ricœur, sometidos dun xeito minucioso a unha sistemática «hermenéutica da sospeita».

Antes de máis, o problema do Suxeito, a súa unidade, a soberanía sobre o obxecto, copa gran parte da literatura posmoderna. A desaparición do autor, a crise do eu unitario e racional así como a emerxencia historicamente situada e datada do «individuo» son algúns dos elementos comprendidos na teoría da subxectividade que levarán o pensamento posmoderno cara a unha crítica da tradición humanista e o seu tema central, o «Home». O punto de vista adoptado pola radicalización da tradición postestruturalista (Foucault, Derrida, Deleuze, Lacan, Guattari...) remítenos á desintegración da visión heroica do suxeito moderno, que xa non é señor da explicación científica e deixa de ser axente efectivo da natureza. A consecuencia directa destes presupostos é a transformación da noción de identidade entendida como fixación e unidade, o advento do novo individualismo occidental (Lipovetsky 1986, Finkielkraut 1987) e os recentes dilemas do eu: o narcisismo, a pluralidade de elección, o cinismo e, sobre todo, a fragmentación das varias posicións do suxeito (Bauman 1992, 1995), a precariedade da súa condición nun mundo dislocado en que está case sempre «fóra de lugar». A obra de Foucault e Derrida, co seu fincapé na fragmentación contemporánea do sentido, na fraxilidade, a perda de fundamentos e a ambigüidade constitutiva da orde simbólica, constituíu un potente lenitivo para a metafísica da presenza e a filosofía holista e teleolóxica, quer individualista, quer comunitarista.

Así mesmo, a Historia como explicación cronolóxica, como correlato linear da supremacía do suxeito cartesiano, debilítase, disólvese a súa teleoloxía do Progreso. $\mathrm{O}$ pensamento posmoderno adopta decididamente a forma dunha «xenealoxía» e unha "arqueoloxía» (Foucault), cuxo postulado é que todos os relatos explicativos, toda forma específica de codificar a temporalidade, no fondo, encobren intereses inconscientes, conflitos de poder e outras formas de saberes. A historia sempre se escribe desde a perspectiva do presente, satisfai unha necesidade do momento. Fronte á historia ontolóxica causal ou á historia oficial, a interpretación xenealóxica esixe a relativización, en graos diversos, da idea clásica de «Verdade». En último termo, en demasiadas ocasións só existe, no sentido que 
Nietzsche atribúe á expresión, «un exército móbil de metáforas» ou "perspectivas» sobre unha realidade infinita. A arqueoloxía constitúese como técnica para descubrir o que está por debaixo do saber histórico, as configuracións nada neutrais sobre cuxo fondo se van interpretar e elaborar os obxectos de cońecemento.

No campo da Gran Teoría entran en crise os conceptos de representación (Rorty) así como os dualismos baseados na dialéctica entre esencia e aparencia (Derrida). A incredulidade respecto ás metanarrativas (Lyotard) e o abandono da distinción clara entre obxecto e suxeito (Baudrillard, Lyotard) supoñen outro distanciamento fronte ao pensamento ilustrado. Epistemoloxicamente, os autores posmodernos rexeitan o suposto moderno de que o actor ten un acceso non mediado — détaché — á realidade; en liñas xerais, seguen a Nietzsche na crítica sobre a autorreflexión, a autoidentidade ou calquera tipo de elemento racionalista que amorteza os instintos físicos vitais (Deleuze, Guattari) e a disposición a vivir e interpretar o mundo sobre a base da pluralidade.

Pola súa vez, a política como proxecto moderno de emancipación universal — «la liberté des Modernes»— é substituída pola atención a unha máis modesta micropoliti$c a$, protagonizada por diversas loitas sociais, fragmentarias e particulares, que irrompen dun xeito coordinado ou descoordinado na arena da acción política. Preséntase unha nova axenda social e política, e o anovado espectro de prácticas políticas de pequenos grupos autónomos ou novas formas emerxentes de «multitude» — desvinculadas xa dos conceptos modernos de «clase», «pobo», «masa» ou «nación» (Negri e Hardt 2000, 2004, 2009)— constitúe un fenómeno xenuinamente posmoderno aínda que, en ocasións, os propios grupos rexeiten esta presentación de inclusión nas coordenadas posmodernas.

Independentemente da posición que se sosteña respecto da súa futilidade ou relevancia, e a reserva que susciten os seus excesos relativistas, non pode ocultarse a pegada intelectual que para a reconstrución do concepto normativo moderno de Cultura —construído como Civilización universal e interpretado a partir do mito do Progreso- este movemento posmoderno deixou. Antes de máis, pola dilución e relativización (que non abolición) de fronteiras entre a Alta Cultura e a cultura popular. Así, fronte ao universalismo da civilización recuperarase o valor das culturas particulares situadas no seu tempo e o seu contexto; fronte ao vangardismo elitista, e o seu correlato da vontade de Estilo que cimenta a soberanía do Autor e a Orixinalidade, oponse unha preferencia pola mestizaxe de tendencias e motivos, a intertextualidade como plural contexto intelectual, presente ou pasado, 
de toda escritura (Kristeva), así como polas técnicas híbridas da colaxe e o pastiche (Jameson). Transunto da crítica da vangarda estética (véxase o cadro 2), aparecerá a crítica da vangarda cultural ou política, a necesidade de rearticulación do nacional-popular e a recuperación da bagaxe gramsciana da guerra de posicións e a hexemonía (Laclau). Todo isto desemboca nunha revalorización da arte pobre, dos obxectos cotiáns, das culturas e linguas minoritarias, na redefinición mesma do que debe ou pode entenderse por arte ou cultura. Máis unha vez, o abandono do exceso de universalismo e formalismo dos modernos (o «Estilo internacional» en arquitectura, por exemplo), da teleoloxía emancipadora da mensaxe profunda - que ha ser desentrañada hermeneuticamente, que ha ser descodificada semioticamentetradúcese nunha nova modestia ou, así chamada dun xeito provocador, «superficialidade». Mais isto, pola súa vez, prolóngase nunha crítica do Xuízo compartido, nunha debilitación do desprezo cara ao pasado da man do Mito do Progreso (i. e.: a idea de que este estilo ou aquela técnica están «superados»). Mais tamén nun rexeitamento da mirada despectiva de moitos dos modernos cara ás culturas populares nas súas diferentes manifestacións, baseándose nun suposto canon artístico cosmopolita de mercado. Finalmente, aplícase unha obsolescencia do «xénero» e das súas regras mediante a hibridación; o pastiche, que xa non mera parodia (Jameson 1991); a apropiación intertextual desprexuizada de materiais heteroxéneos exentos de nobreza artística, de beleza canónica.

Pluralismo radical e crítica de todo holismo homoxeneizador son temas que deixarán fonda pegada no concepto contemporáneo de cultura. A reprobación das modernas ideas de vangarda, progreso e revolución abre a porta á crítica do elitismo cultural, do Estilo con maiúscula, dos xéneros e as súas regras estritas, ás institucións que velan polo «canon occidental», ao «orientalismo». Con isto ábrese paso á irrupción da arte popular — tamén a chamada «étnica»; isto é, a dos outros — das minorías, ao informalismo e ao patchwork, ao pluralismo e a síntese de culturas e xéneros e soportes (Pollock 1996, 1999; Best e Kellner 1997; Máiz 2018a). No posmodernismo recupéranse ademais e radicalízanse temas varios do Romanticismo: o gusto pola ironía, a arte como proceso inacabado e non como obxecto finalizado, a creación compartida (fronte á soberanía do autor) co intérprete ou o lector. E, sobre todo, non debe esquecerse un aspecto fundamental que adoita pasarse por alto: «atento ás rúas e desencantado, o posmodernismo opta pola cultura como conflito real para alén de toda imaxinaria reconciliación» (Eagleton 2000: 41). 
Todos estes temas resultarán capitais para a relectura contemporánea do concepto de «cultura», como se verá nos debates que xiran arredor do multiculturalismo e o nacionalismo... e nalgunha corrente emerxente da ciencia política. Nesta discusión, en efecto, rescatando temas do Romanticismo e do posmodernismo - ao fío da crecente mobilización política de minorías étnicas, culturais, nacionais e sexuais, así como de formas de vida alternativas etc.- - o concepto de cultura xa non designará un estándar elitista e excluínte na súa autorreferencialidade. Senón un conxunto continxente e inesencial de elementos de dotación de sentido — crenzas e prácticas semióticas - que evoluciona no tempo e no espazo, a partir do pluralismo e o conflito interiores, así como de intercambios con outras culturas, mediante o cal un grupo de seres humanos regula e orienta a súa vida individual e colectiva. Velaquí a contribución incontestable do posmodernismo: as identidades contemporáneas xa non presupoñen culturas e traducións continuas, nin totalidades nas cales mergullarse acriticamente dun xeito pasivo, nin compartimentos estancos fronte a outras culturas. Hai algo máis ca decadencia e ruína nesta existencia da nosa época fragmentada e transfronteiriza, "hai algo que xorde» (Clifford 1998: 12). A cultura xa non é máis un espazo reservado ás mellores creacións de Occidente, senón que, en canto que constitúe un conxunto de marcos de significación nos cales vive a xente e forma as súas conviccións, as súas identidades e as súas solidariedades, reclama unha política que non considere a afirmación étnica, relixiosa, lingüística ou nacional como un residuo irracional, arcaico e conxénito que ten de ser suprimido e transcendido..., senón unha realidade debatida e acordada (Geertz 2000: 236). Este é, precisamente, o horizonte político que, sobre tales bases intelectuais e ante os novos desafíos e conflitos emerxentes no mundo contemporáneo, o multiculturalismo inaugurou.

MODERNISMO

\begin{tabular}{cc}
\hline Progreso & Fin da historia, distorsión temporal \\
\hline Universalismo & Particularismo \\
\hline Ascetismo & Hedonismo, narcisismo \\
\hline Sociedade industrial & Sociedade da información, cibercultura \\
\hline Gran narrativa & Deconstrución \\
\hline Orixinalidade, autenticidade & Pastiche, colaxe \\
\hline Xéneros, regras & Anticonvencionalismo, metaficción \\
\hline
\end{tabular}




\begin{tabular}{cc}
\hline Vangarda, elitismo & Arte popular \\
\hline Teleoloxía emancipatoria, mensaxe & Escepticismo, ironía, humor negro \\
\hline Experimentación & Copia, sincretismo \\
\hline Obxecto, obra & Proceso, happening, performance \\
\hline Estilo & Intertextualidade, eclecticismo \\
\hline Autor & Lector, espectador \\
\hline Estrutura & Fragmentación, dislocación \\
\hline Ruptura/Provocación & Copia, apropiación, parodia \\
\hline Profundidade & Superficialidade, simulacro, hiperrealidade \\
\hline Opacidade/Hermetismo & Falsa accesibilidade \\
\hline Formalismo & Informalismo
\end{tabular}

Cadro 2. Os campos semántico-conceptuais da idea de cultura no modernismo e no posmodernismo. Fonte: elaboración propia

\section{O CONCEPTO PLURALISTA DE CULTURA NO MULTICULTURA- LISMO RECENTE}

O concepto de «cultura» incorporado polo multiculturalismo recolle inicialmente a escisión romántica e posromántica entre Zivilisation, modo de vida universal debedor da ciencia e da técnica, e Kultur, isto é, o mundo do sentido, signos lingüísticos e símbolos dos pobos, comunidades, grupos étnicos e nacións particulares. Mais non se reduce a ela, pois, como veremos, supéraa, xa que non se limita a substituír a unha pola outra, senón a abordar normativamente a tensión creativa entre ambas. $\mathrm{O}$ multiculturalismo non nega a existencia dunha identidade humana común, senón que a constrúe, en contra do monismo, da man dun peculiar universalismo pluralista, como unha realidade complexa de, por unha banda, a natureza humana universal (capacidades, necesidades, valores) e, pola outra, trazos culturalmente específicos e particulares. Isto é, postula un thick and thin, unha dimensión tenue de valores e principios para a vida en común compartida polos seres humanos e unha dimensión densa do propio modo de vida, historia e cultura de cada comunidade que resulta decisiva para a definición dos valores e os bens (Walzer 1994, 2004). 
Mais tamén, e a diferenza do relativismo e a inconmensurabilidade radical cos que moitas veces se identifica, por mor das súas titubeantes formulacións primeiras, o multiculturalismo máis recente non comporta a aceptación acrítica de calquera interpretación particular das ideas de ben. En suma, desde o momento en que a) mantén a posibilidade duns mínimos morais universais compartidos, e b) estende, alén diso, o pluralismo e conflito cara ao interior da comunidade, o multiculturalismo máis recente distánciase do inicial comunitarismo que o caracterizaba nos seus comezos; de aí a súa tipificación, por veces, como interculturalismo.

Parte dos problemas e das insuficiencias da primeira teoría política do nacionalismo liberal e o multiculturalismo intercultural (de aquí en diante, multiculturalismo I) derívanse dunha concepción das nacións e as comunidades culturais como grupos prepolíticos, resultado obxectivo dos «feitos» sociais, demográficos e étnicos diferenciais. A filosofía política e as ciencias sociais máis recentes puxeron de relevo, con todo, que boa parte da primeira teoría política do nacionalismo e o multiculturalismo resultaba debedora de asuncións claramente insostibles (Máiz 2012): 1) cara ao interior, considerábanse as culturas e as nacións como totalidades orgánicas, integradas e homoxéneas, ignorando ou pońendo en segundo plano a diversidade interna, a pluralidade de interpretacións e proxectos concorrentes, así como o conflito entre eles; 2) cara ao exterior concibíanse as culturas e as nacións como entidades claramente individualizables e distinguibles, exacerbando a diferenza que separa o «nós» do «eles», o «propio» do «alleo», subestimando os elementos comúns; 3 ) nacións e culturas eran consideradas (e aínda o son en boa medida) como entidades definitivamente cristalizadas na historia, como conxuntos dados de antemán e esencialmente alleos a calquera eventual proceso de evolución, mudanza ou reformulación; 4) isto traduciríase, pola súa vez, en que a pertenza se equiparaba á socialización pasiva na tradición, na inmersión e aceptación acrítica das pautas e formulacións proporcionadas polos legados históricos, á marxe de calquera participación libre e creativa dos integrantes delas na súa constitución; 5) o cal se prolongaba nunha concepción museística e conservacionista da cultura das nacións e os grupos étnicos, coma se o debate, a mudanza, a mestizaxe ou a incorporación as puxesen en perigo, en risco de «contaminación», de «dexeneración», e debesen ser blindadas na súa suposta pureza prístina; 6) todo isto abocaba a unha perspectiva das identidades colectivas de grupo cultural ou nación como identidades excluíntes, separadas, incomunicadas, alumando, en rigor, unha sorte de multicomunitarismo, segundo un ideal de nacións e comunidades culturais a floreceren unhas a carón doutras, de costas, 
encerradas as primeiras no seu propio Estado nacional homoxéneo, as segundas nos seus modos de vida «auténticos» sempre ameazados; 7) finalmente, isto comportaba unha hiperculturización comunitarista e proteccionista que deixaba escasa marxe para relacionar as demandas de recoñecemento con polo menos tres dimensións básicas e estreitamente relacionadas da política democrática: a mudanza cultural e a creatividade, a igualdade de oportunidades e a deliberación política.

De maneira moi diferente, a ciencia social contemporánea, da man dunha óptica construtivista de varia índole, insistiu na natureza non de obxectos, senón de procesos complexos, continxentes das nacións e culturas, na súa apertura e indeterminación, de resultas tanto da súa natureza interna plural e conflitiva como da inevitable dimensión relacional de contactos, experiencia histórica e fluxos de comunicación con outras comunidades (Brubaker 2004; Hale 2008). Esta natureza dinámica e contestada, isto é, en rigor política das nacións e as culturas, resulta decisiva desde o punto de vista normativo que aquí interesa, pois sitúa en primeiro plano, fronte ao vocabulario do reconecemento e a autenticidade (Taylor 1992), a atención aos procesos de construción nacional, a pluralidade interna das culturas, a posibilidade de identidades superpostas, a igualdade de oportunidades na construción da propia cultura ou nación (Norman 1995, Carens 2000, Benhabib 2002). A revisión que se apunta na ciencia social e na teoría política é, xa que logo, substantiva, pois, entre outras cousas, dificilmente se pode dar conta normativa dos procesos de construción nacional e recreación cultural sen unha previa revisión da concepción de comunidades e culturas como feitos obxectivos, en boa medida dados de antemán («taken as givens» [Kymlicka 1995: 184]).

Deste xeito, pódese comprobar ata que punto no multiculturalismo posterior (multiculturalismo II ou interculturalismo) se abandonou, en conexión polo menos parcial coas achegas do Romanticismo (Taylor) e o posmodernismo, o concepto reificado e holista de cultura do comunitarismo ou do «esencialismo antiilustrado", a cultura como unha totalidade orgánica, esencialmente cristalizada na historia, coherente no seu interior e nidiamente diferenciada cara ao exterior, que aínda constitúe o albo dalgunhas críticas prominentes contemporáneas (Barry 2002).

Este concepto reformulado de cultura afástanos, xa que logo, tanto do comunitarismo como do liberalismo individualista, e iso no que respecta á relación entre individuo e contorna cultural, igual ca ao nexo entre comunidade e cultura. En principio, a argumentación multiculturalista asume que os individuos teñen un interese funda- 
mental na continuación das súas prácticas e crenzas culturais porque 1) forma parte dunha cultura subministrar o contexto desde o que realizar escollas e tomar decisións; 2) a pertenza a unha comunidade cultural constitúe parte da vida boa, da vida que paga a pena que os cidadáns vivan; 3) o apoio dunha comunidade cultural móstrase como catalizador dos bens do autorrespecto e a dignidade, e 4) a xustiza, incluída a xustiza igualitaria, non pode ser neutral culturalmente, pois posúe unha compoñente de sentido, mediado e «interpretado» polas culturas ás que se aplica.

Mais a seguir, porén, reformúlase dun xeito notorio o inicial argumento multiculturalista: unha vez que os seres humanos aspiran a se desenvolver persoalmente, a cultura debe ser fonte de autonomía, creatividade e liberdade. Esta argumentación de Taylor no seu capital The Sources of the Self(Taylor 1989) matiza dun modo importante a lectura habitual, como apoio xenérico á «supervivencia cultural» do seu texto Multiculturalism and "The Politics of Recognition" (Taylor 1992), así como o concepto mesmo de autenticidade como fidelidade pasiva e acrítica á propia cultura, pois non todo contexto cultural fundamenta a autonomía individual (Parekh 2000: 57), nin o fai no mesmo grao.

E, no que se refire á relación entre cultura e comunidade que resulta das características anteriores, é esta unha relación complexa; en concreto: as culturas non son congruentes con grupos de poboación e non é posible unha descrición indisputada da cultura dun grupo humano. O concepto de comunidade cultural ou grupo cultural é problemático e continxente: un conxunto de xente pode compartir unha cultura, unha lingua, uns mitos e símbolos; outros, para alén diso, poden compartir unha relixión; outros, unha etnicidade común. Algúns poden manter a propia cultura, mais perder os lazos coa súa comunidade de orixe (inmigrantes ou refuxiados) por razóns políticas ou económicas; ou, á inversa, pódense manter vencellos comunitarios, pero rexeitarse a cultura «propia» por mor dos termos en que vén formulada. A cultura é «un sistema de sentido e significado creado historicamente, un conxunto de crenzas e prácticas arredor das cales un grupo de seres humanos comprende, regula e estrutura a súa vida individual e colectivamente» (Parekh 2000: 218). A cultura, en suma, é o mundo de sentido que un grupo posúe - sempre dun xeito heteroxéneo e en desigual medida e aceptación crítica-, nunca o que un grupo é. Menos aínda é cultura ningunha propiedade exclusiva dun grupo étnico, nin ningún grupo étnico posúe unha cultura exenta de ambigüidade e interpretacións plurais e contestadas. 


\begin{tabular}{cc} 
MULTICULTURALISMO I & MULTICULTURALISMO II \\
\hline Holismo, homoxeneidade & Pluralismo, conflito interno \\
\hline Fronteiras impermeables (propio/alleo) & Permeabilidade, mestizaxe \\
\hline Historicismo, sutura, esencialismo & Proceso, apertura, continxencia \\
\hline Socialización, autenticidade & Creación, autonomía, crítica \\
\hline Conservación, fidelidade & Participación, mudanza \\
\hline Identidades excluíntes & Identidades superpostas \\
\hline Representación descritiva & Contestación, deliberación \\
\hline Multicomunitarismo & Interculturalismo \\
\hline Cadro 3. A evolución do concepto de cultura no multiculturalismo. Fonte: elaboración propia
\end{tabular}

Ora ben, esta radical reformulación do concepto de cultura por parte do multiculturalismo II ou interculturalismo posúe notables consecuencias normativas para a política e as políticas públicas que se levan a cabo no seu nome. A tradicional perspectiva top-down dará paso a unha nova óptica bottom-up na que os mecanismos participativos e deliberativos, as policy communities e a gobernanza horizontal substitúen a tradicional perspectiva de goberno xerárquico e verticalista. Dunhas políticas públicas para as minorías (asimilación, integración) transitarase a políticas públicas coas minorías (autonomía, deliberación, participación). Podemos sintetizar brevemente algunhas das transformacións inducidas polo novo concepto pluralista e construtivista de cultura. Antes de máis, o multiculturalismo comporta acomodación, isto é, renunciar á noción de cidadanía só no seu sentido exorbitante: o que se traduce en uniformidade, no suposto de que todos os cidadáns han ter exactamente os mesmos dereitos e deberes, pois isto non deixa lugar para a variedade de problemas e demandas específicos que xorden dos diferentes modos de vida. En suma, abandonar os argumentos de propiedade territorial que se dan como autoevidentes: «este é o noso país e así facemos as cousas aquí» ou o "somos máis e estabamos aquí antes» (Barry 2002: 232). Respecto igual, nunha sociedade multicultural, comporta respecto aos diversos trazos diferenciais e obrigas culturais específicas. Isto require, desde o punto de vista positivo, que en principio todos os grupos deban ter unha oportunidade igual de viviren o tipo de vida que a súa cultura prescribe segundo eles mesmos libremente a interpretan. E, desde o punto de vista negativo, que non deban estar sometidos, agás por 
causas maiores, a requirimentos legais que comporten violación fundamental das súas conviccións e modos de vida.

Ora ben, a consideración das culturas como plurais no seu interior, abertas cara ao exterior, contestables e dinámicas implica que a acomodación non debe asumir como dados, fixos e inmutables os trazos, prácticas e obrigas internas do grupo. Nin tampouco consideralos como espazos alleos á crítica, á negociación e aos arranxos de acomodación (Laden e Owen 2007). A perspectiva, tamén aquí, ha ser de inclusión irrestrita na esfera pública e non de xerar ámbitos exentos ao escrutinio normativo e democrático. Isto supón calibrar e sopesar os custos da mudanza dunha práctica ou costume do grupo minoritario (dependendo da súa centralidade para a propia cultura) fronte á mudanza correlativa que aquela comporta da norma derivada da cidadanía igual (dependendo da centralidade desta norma para os valores democráticos da cidadanía) (Miller 2002).

Todo o cal se traduce no abandono da preeminencia da perspectiva legalista e xurídica —isto é, a identificación dos principios relevantes e a súa aplicación a casos concretos- e na súa substitución por unha óptica abertamente política, democrática e deliberativa. Así, fronte á excesiva xudicialización do multiculturalismo inicial (no cal a maioría das disputas se resolven mediante decisión dos tribunais de xustiza), ha de postularse a súa inclusión democrática activa; isto é: construír as demandas como obxecto de disentimento, conflito e decisión, no seo dun proceso político de diálogo e debate. Pois do feito de as culturas non seren totalidades homoxéneas derívase que os principios multiculturais deben conectarse cos principios de cidadanía republicana, decisión e deliberación. Posto que só o debate democrático pode achegar o esclarecemento e a información necesarios (non só das preferencias, obrigas ou trazos do grupo, senón tamén da intensidade e centralidade destes para a súa cultura) co obxecto de aplicar o principio de igualdade de oportunidades nun contexto complexo como é o multicultural, isto devólvenos ao espazo dunha esfera pública ampliada á sociedade civil. Por iso a dimensión democrática en sentido republicano é central para as políticas interculturais porque, fronte á imposición dunha idea de igualdade universalista e sen matices ou dunha cultura nacional maioritaria, se institucionaliza un proceso de cuestionamento das regras herdadas de recoñecemento, dos propios contidos das culturas maioritarias, mais tamén das minoritarias, e de negociación mediante procedementos de proba e erro da convivencia e superposición de identidades 
(Tully 2002, Laborde 2008). O cal nos conduce, antes de máis, a un principio de deliberación «externa»; isto é, inclusión dos modos de vida na esfera pública dunha comunidade política entendida como un conxunto de maiorías, minorías e cidadáns singulares (nacionalismo liberal). Mais isto, pola súa vez, comporta dúas cousas: a) que debe asumirse que a presenza normativa do pluralismo supón a modificación parcial das institucións políticas e o ordenamento xurídico maioritarios e a posta en práctica de reasonable accommodations, e b) que, fronte ao modelo integracionista, que sostén que a maioría establece unilateralmente os criterios de inclusión, se postule un modelo autonómico, que outorgue ás minorías a capacidade de codecidir e coxestionar, conxuntamente coa maioría, os principios de xustiza que han de se aplicar nos diferentes bens que están en xogo. Isto, pola súa vez, e fronte ao mero recoñecemento, supón a reciprocidade dunha esixencia de negociabilidade de identidades e trazos culturais, discernindo aqueles que son consubstanciais ao grupo doutros máis superficiais ou que dependen dunha lectura contestada da tradición: a inclusión implica mudanzas e modificacións consensuadas tanto para as maiorías como para as minorías. Desde esta perspectiva, a necesidade de potenciar o asociacionismo das minorías vulnerables e a intermediación cultural entre os grupos pasa ao primeiro plano.

Os argumentos anteriores reenvíannos, como vemos, ao estreitamento de lazos entre política democrática e cultura, ao pluralismo e á deliberación interna ao grupo ou comunidade e á garantía, por parte dos poderes públicos, do pluralismo e da participación e o debate internos, fronte a versións tradicionalistas e, se é o caso, autoritarias. As políticas interculturais non poden recoñecer prácticas e institucións desigualitarias, vexatorias, humillantes ou opresivas, non tanto por mor de vulneraren os usos da maioría como por razóns mínimas universais que afectan á vida interior dos grupos (Parekh 2000: 272, Barry 2002: 275, Laborde 2008, Máiz 2012, 2018b). Así, do mesmo xeito que o multiculturalismo debe supor o apoderamento, mediante a inclusión na esfera pública, das minorías étnicas, culturais etc., tamén debe evitar a opresión interna ao grupo. Neste sentido resulta vital garantir o apoderamento democrático das minorías e das voces portadoras de diferentes versións no interior desas comunidades, apoiando a súa capacidade de revisión e autonomía, especialmente na xente nova e nas mulleres. Todo o cal, finalmente, nos devolve, para alén do multicomunitarismo, á dimensión universalista das irrenunciables condicións de deliberación da ética discursiva e da igualdade democrática, que comportan o cumprimento de tres condicións nor- 
mativas indispensables: a) reciprocidade igualitaria: non-discriminación dos membros das minorías fronte á maioría en virtude da súa pertenza comunitaria; b) adscrición voluntaria: fronte á adscrición étnica obrigatoria, as e os cidadáns non deben ser automaticamente asignados a un grupo cultural, relixioso ou lingüístico en virtude do seu nacemento, senón que debe permitirse a liberdade de opción dos pais, inicialmente e persoal na idade adulta, e c) posibilidade de abandono do grupo sen sancións exorbitantes así como dereito de pertenza flexible (mestizaxe, matrimonios mixtos non arranxados, liberdade de crenzas e modos de vida etc.) (Benhabib 2002: 19).

\section{A CRISE DA DICOTOMÍA «NACIONALISMO CÍVICO»/«NACIO- NALISMO ÉTNICO-CULTURAL»}

A tarefa de impor unha orde de intelixibilidade, de dotar de sentido a esquiva multiplicidade de nacionalismos, e, ao tempo, de postular unha xerarquía normativa que permita discernir entre o nacionalismo bo (o «noso», occidental, liberal, tolerante etc.) e o perigoso (o dos «outros», «oriental», autoritario, irracional etc.), a partir da súa clasificación empírica, levouse a cabo relacionalmente mediante o xogo de diferenzas entre significantes. A análise semiótica sinala que os códigos consisten en relacións convencionais e arbitrarias (no sentido de Saussure; isto é, non naturais, senón artificiais) entre significante e referente, así como que detrás de toda narrativa existe unha estrutura máis profunda que organiza o mundo discursivo en estruturas simbólicas. Os símbolos, pola súa vez, insírense en conxuntos de códigos binarios (sagrado/profano, cru/cocido, ben/mal...) e son eses conxuntos de oposicións os que en boa medida organizan os discursos.

A dicotomía de «nacionalismo cívico»/ «nacionalismo étnico-cultural» formúlase desde un lugar moi preciso, desde unha posición en absoluto neutra nin equidistante entre os seus polos, a saber: desde o nacionalismo do Estado-nación. Desde un nacionalismo de Estado implícito que dá por suposta a coincidencia entre fronteiras políticas e culturais, entre Estado e nación, e considera non problemática a cuestión do demos, de quen conforma o pobo sobre o que se alza a lexitimidade do Estado. O expediente non é sinxelo, pois tras a, eficacísima politicamente, autoevidencia de tal clasificación reside toda unha complexa operación discursiva de articulación de varios campos semántico-conceptuais. Esta 
escisión dualista entre «nacións étnicas» e "nacións cívicas», tamén formulada como «nacións culturais» e «nacións políticas», toma como base as substantivas diferenzas entre as tradicións dominantes "francesa»e «alemá» da nación, mais prolóngase, porén, e isto é o decisivo, nunha máis detallada dicotomía que transforma as diferenzas de grao en insuperables diferenzas de modelo — nacionalismo (cultura) vs. patriotismo (democracia) - e certas diferenzas de contexto en discrepancias sobre principios esenciais, alumando un bipolar e escindido mundo de nacións e nacionalismos.

E isto realízase mediante a superposición e cohonestación de dous códigos binarios complementarios. En primeiro lugar, a través da incorporación e o reforzo dunha antítese tan redutiva e falaz como consolidada ata hai ben pouco na historia do pensamento político, filosófico e estético, a saber: unha contraposición elemental e sen gradacións entre Romanticismo e Ilustración que xa criticamos e matizamos no primeiro apartado. En segundo lugar, mediante o contraste bipolar liberalismo/autoritarismo, calcado sobre o dualismo histórico-político Francia/ Alemaña, de tal sorte que a unha idealización liberal de Occidente se contrapón un arquetipo autoritario de tradición «orientalista» no sentido de Edward Said: nós/eles, civilizados/bárbaros, tolerantes/intolerantes etc. (Said 1978).

A reformulación, de común acordo, destes tres eixes bipolares (véxase o cadro 4): Francia/Alemaña, Romanticismo/Ilustración e liberalismo/autoritarismo, permite a imbricación e superposición de series binarias que arrastran, cada unha delas, conxuntos de novos pares semántico-conceptuais. Así, en primeiro lugar, o eixe Francia/Alemańa prolóngase na contraposición entre as nocións de liberdade, cidadanía, Estado e nación entre Oriente/Occidente; o ius soli, isto é, a cidadanía en virtude da soa residencia nun territorio, fronte ao ius sanguinis, a cidadanía derivada da común ascendencia étnica, quer «racial», quer cultural e lingüística; ao Estado-nación, que constrúe desde arriba a nacionalidade con criterios cívicos e inclusivos, opóńense as nacións sen Estado en demanda da súa autodeterminación a partir de determinacións étnicas excluíntes; ao progreso como horizonte de converxencia última civilizatoria, a decadencia oriental ou o seu reflexo na «decadencia de Occidente»; á civilización universal e cosmopolita, a cultura como Kultur, isto é, etnicamente delimitada, historicista e particularista. A isto superponse, en segundo lugar, como eixe adicional, unha formulación dicotómica e caricaturesca da oposición Romanticismo/Ilustración, que se artella 
sobre o dualismo emoción/razón, relixión/reencantamento do mundo, fronte a secularización e desencantamento (Entzauberung der Welt), propios da modernidade ilustrada; os conceptos de vida e organismo fronte aos de mecanismo, máquina e técnica; o retorno á natureza, formulada como natureza comunitaria, isto é, como contexto étnico-cultural da identidade, representado nas tradicións populares, fronte á artificialidade do contrato e o dereito positivo; a cultura enraizada na comunidade portadora de valores propios contra a política desasida da moral; a tradición fronte á modernidade; o destino dos pobos, o Volksgeist, o espírito único e irrepetible de cada nación, fronte á liberdade de escolla, a continxencia indeterminada produto da vontade irrestrita; a comunidade que dota de sentido compartido, solidariedade e altruísmo patriótico, de valores e dunha idea holista de ben colectivo dos cidadáns, fronte á sociedade integrada por individuos illados, descontextualizados, competitivos, únicos xuíces dos seus propios intereses egoístas; a fidelidade á tradición comunitaria propia fronte á liberdade («dos modernos»), a liberdade negativa fronte ao Estado neutral; a autenticidade e o respecto pasivo á cultura e as raíces propias fronte á autonomía, a capacidade individual de fixar os fins, de revisar os valores herdados, a disposición á crítica, a capacidade de "xuízo». Finalmente, en terceiro lugar, o par liberalismo/autoritarismo pecha a cadea binaria de equivalentes, de tal sorte que á raza ou mesmo á cultura concibida de forma esencialista e determinista como exclusión do «outro» —non só diferente, senón tamén «inferior»— se contrapón a libre vontade da cidadanía; á reacción, ao rexeitamento global da modernidade, oponse a revolución liberal, como síntese suprema de vontade e razón; á nación como unánime totalidade orgánica (das Volk), o pobo («We the People...») como conxunto de cidadáns singulares, dotados de dereitos e intereses; fronte ao chauvinismo patrioteiro, o patriotismo cívico ou constitucional, como adhesión aos principios políticos e xurídicos do Estado liberal; á cega adhesión ao «Destino» ou a «Misión» da nación, a deliberación e a discusión na esfera pública, na prensa ou no Parlamento; ao populismo oporase o civismo e un concepto de cidadanía forte; por último, ao liderado carismático, á adhesión ao líder mediante aclamación, o liderado legal racional sometido a responsiveness e accountability.

A articulación destes tres eixes configura un en extremo complexo panorama dicotómico, que tratamos de sintetizar no cadro 4 . Ora ben, como xa apuntamos, esta dicotomía non é de ningún modo neutral, non divide o mundo dos na- 
cionalismos en dous modelos dotados de semellante valor. Máis aínda, formúlase desde un punto de vista normativo que fica cego ante a eficacia naturalizadora do mito, que diría Barthes, que presenta como evidente na súa despregadura a división do mundo nacionalista en dous campos desiguais. Isto é, o estereotipo que nos ocupa formúlase sobre a base do nacionalismo cívico para exorcizar, desprazándoas enteiramente ao outro campo, todas as dimensións da «etnicidade»: mitos, símbolos, historia, cultura etc. Deste xeito, depurado de contido étnico e cultura, o nacionalismo cívico devén, mediante este dispositivo discursivo, plenamente "político»; dito doutro modo, centrado de maneira exclusiva na libre vontade da cidadanía democraticamente expresada. En suma, o nacionalismo cívico devén de feito puro "patriotismo» (ć́vico, republicano, constitucional etc.), «que non ten ren en común co nacionalismo» (Viroli 1995: 210). Desconéctanse así cidadanía e nación, a dimensión de pertenza á república con respecto á contorna histórica e cultural específica da nación. Desta sorte, a cidadanía individualízase e descontextualízase culturalmente, universalizándose. A asimilación na cultura maioritaria preséntase como un feito natural, resultado do trade-off mediante o cal se procede á constitución dun Estado de cidadáns libres e iguais ante a lei, supostamente «neutral» en cuestións culturais e lingüísticas. E, finalmente, pola súa banda, a nación desrepublicanízase, despolitízase e devén o depositario pasivo e vicario da tradición e do mito da común ascendencia.

\begin{tabular}{cc} 
NACIONALISMO ÉTNICO & NACIONALISMO CÍVICO \\
\hline- & + \\
\hline Romanticismo & Ilustración \\
\hline Emoción & Razón \\
\hline Relixión & Secularización \\
\hline Kultur & Zivilisation \\
\hline Natureza & Contrato \\
\hline Organismo & Mecanismo \\
\hline Raza & Vontade \\
\hline Cultura & Política \\
\hline Nación sen Estado & Estado-nación \\
\hline Tradición & Modernidade
\end{tabular}




\begin{tabular}{|c|c|}
\hline Destino & Continxencia \\
\hline Asignación primordial & Elección \\
\hline Decadencia & Progreso \\
\hline Reacción & Revolución \\
\hline Nación & Pobo \\
\hline Comunidade & Sociedade \\
\hline Campo & Cidade \\
\hline Fidelidade & Liberdade \\
\hline Autenticidade & Autonomía \\
\hline Fusión & Crítica \\
\hline Chauvinismo & Patriotismo \\
\hline Costume & Lei \\
\hline Orixe & Futuro \\
\hline Adhesión & Deliberación \\
\hline Liderado carismático & Liderado legal-racional \\
\hline Autoritarismo & Liberalismo \\
\hline Populismo & Civismo \\
\hline Holismo & Individualismo \\
\hline Ius sanguinis & Ius soli \\
\hline Particularismo & Universalismo \\
\hline Oriente & Occidente \\
\hline Alemańa & Francia \\
\hline
\end{tabular}

Cadro 4. Principais dimensións da dicotomía nacionalismo étnico/nacionalismo cívico. Fonte: elaboración propia.

A distinción entre nacionalismo étnico e nacionalismo cívico, porén, presenta moi serios problemas empíricos e teóricos, algúns dos cales amosaremos a seguir. Constitúe mérito indisputable de Anthony Smith realzar a indisociable relación entre as dimensións étnico-cultural e política de toda nación. En efecto, malia aceptar nalgún momento un uso matizado da distinción de "concepcións», que non de definicións, étnica e cívica da nación (Smith 1991: 91; 1996: 9), toda a súa obra supón, en boa medida, unha deconstrución sistemática de tal dualismo, ao salientar a compoñente étnica que reside na base das nacións como fenóme- 
nos políticos da modernidade. A obra de Anthony Smith (1986, 1999, 2000), alén diso, non só subliña a decisiva compoñente étnica (no sentido de ethnie, de comunidade cultural) das nacións —isto é, o conxunto de mitos, lembranzas e símbolos que os intelectuais achegan na procura de lexitimación da nación-, senón que destaca, así mesmo, o primordial carácter para a constitución moderna da nación, da índole desa herdanza do capital de mitos e narrativas herdados para a orientación política da nación. Cada proceso de construción nacional procede mediante unha articulación complexa da etnicidade achegada (redescuberta, seleccionada, inventada) polos intelectuais fundadores e as vicisitudes políticas e institucionais posteriores. De aí que resulte va toda pretensión de distinguir o cívico do cultural, pois a versión cívica atópase influenciada, en ocasións mesmo hipotecada, pola textura, a estofa, por así dicilo, dos legados étnicos, en canto produto, pola súa vez, dos intelectuais nacionalistas e prenacionalistas. De aí ese desprazamento, no decurso da obra deste autor, do nacionalismo ás nacións e das nacións ás comunidades étnicas (ethnies), e a postulación, fronte á dicotomía dos modelos étnico/cívico, de dous camiños ou rutas (que non arquetipos) alternativos cara á nacionalidade: a de incorporación burocrática desde arriba e a mobilización vernácula desde abaixo.

Vexamos, pola nosa banda, seguindo as incitacións de Smith da man do que el denomina unha «socioloxía histórica das nacións» (Smith 1998: 190), algúns dos problemas da popular dicotomía, comezando polos empíricos para abordar logo os teóricos e os normativos. Antes de máis, unha constatación imponse na máis sólida e recente (mesmo non tan recente) bibliografía sobre os nacionalismos: todos os nacionalismos cívicos occidentais posúen unha indeclinable compoñente étnica e cultural, como ilustran con claridade algúns dos casos máis exemplares que podemos revisar brevemente.

Francia, que constitúe o exemplo par excellence de nacionalismo cívico, foi fundada sobre a inicial exclusión relixiosa, constituíndo o enfrontamento histórico entre católicos e protestantes un auténtico motor do proceso de nation-building e state-building. A creación dos «franceses» posúe, como Anthony Marx mostrou, unha componente histórica fundamental: a unificación, nos albores da modernidade, dunha nación católica, simbolizada no mito de Xoana de Arco, fronte aos protestantes hugonotes, no interior, e ingleses, como inimigos externos (Marx 2003). Mesmo durante a Revolución Francesa, quintaesencia do republicanismo cívico, as 
dimensións étnicas e culturais desempeñaron un papel de certo relevo. No propio Sieyès, pouco sospeitoso de veleidades organicistas, poden rastrexarse ocasionalmente as pegadas do mito fundador da confrontación entre os plebeos galos e os aristócratas francos: «Por que non restituír aos bosques da Franconia todas esas familias que conservan a enlouquecida pretensión de seren descendentes da raza dos conquistadores? [...] Se quixésemos facer distincións de orixe, non poderiamos asegurarlles aos nosos concidadáns que o que se remonta a galos e romanos posúe polo menos tanta liñaxe coma o dos sicambros, vándalos e outros salvaxes saídos dos bosques da Xermania?». E, malia as raíces romanas predominaren dun xeito innegable como referencia histórico-discursiva do republicanismo xacobino, outra liña discorre, con todo, na sombra en que Vercingetorix, o "galo gálico», as orixes galas da Francia auténtica, desempeñan un papel non desbotable na construción da Nation Une. Será, porén, co Imperio e a Restauración, especialmente coa historiografía romántica de Thierry, cando, fronte ao patriotismo republicano e cívico de Michelet, se introduza o tema da «loita de razas» como motor da historia francesa, e a fidelidade á «raza primitiva», e o mito fundador céltico que devolve ao tronco común ario e, xa que logo, ao pé de igualdade con Alemaña, a nación francesa. Mesmo en relatos históricos tan influentes como o de Guizot reverbera o conflito mítico entre francos e galos, entre nobres e servos («a race conquise») (Poliakov 1971). O influxo do mito céltico das orixes, na versión dos Reynaud e Martin, sobre o republicanismo francés a medida que avanza o século ilustra o escenario étnico do máis «cívico» dos nacionalismos. A presenza dun «patriotismo republicano céltico» exemplifica a inseparabilidade entre a dimensión histórico-cultural e mítica e a dimensión cívica. As vicisitudes do ius soli testemuñan, así mesmo, os límites do patriotismo cívico francés: rexeitado por Napoleón e substituído polo ius sanguinis, non sería ata a Terceira República cando se readoptaría, se ben xa nun contexto de conflito con Alemaña. E, como Brubaker amosou, a súa recuperación formaría parte dun indoutrinamento — «moral and civil indoctrination» (Brubaker 1992: 45) - mediante un sistema nacional de ensino que impón unha lingua, un relato histórico e uns mitos e símbolos comúns para todos os franceses. A lenta nacionalización de Francia fronte ás nacionalidades e rexións internas, entre 1880 e 1910, como Eugen Weber mostrou na súa obra clásica, fusionou o patriotismo cívico con vertebración mediante infraestruturas viarias de unificación territorial, o sistema educativo xeneralizador da lingua, a historia nacional e os símbolos da na- 
ción así como o exército como instrumento de socialización nacionalitaria (Weber 1976: 493; 1991: 241). Finalmente, o affaire Dreyfus e o antisemitismo de Action française non farían senón actualizar o antisemitismo xa presente nunha tradición que se mantivo mesmo durante os anos da Revolución.

No caso do Reino Unido, a construción histórica do Estado e da nación como nación protestante fronte aos católicos ingleses, irlandeses ou, como inimigo externo, os franceses patentiza a exclusión orixinaria que hipoteca o carácter supostamente cívico do seu patriotismo (Marx 2003). Linda Coley amosou como no enfrontamento histórico con Francia a dimensión étnico-cultural se sitúa no núcleo mesmo da pertenza reservada aos true born Englishmen, de tal sorte que a construción da British nation se forxa en boa medida da man dun proxecto político e cultural antirrevolucionario. No imperio, a política de inmigración, unha política que permitía aos súbditos da Commonwealth chegar a ser British mais nunca English mostra de xeito patente as imbricacións cívico-étnicas. A Aliens Act de 1905, dirixida contra os xudeus da Europa do leste, e a British Nationality Act de 1981, debedora das ideas racistas de Enoch Powell e que derrogaba de feito o ius soli, amosan un retrato moito máis etnicista ca cívico da construción nacional inglesa.

Nos EuA, a exclusión fundacional das nacións indias sería o prolegómeno da xénese dunha nación arredor de criterios étnicos ben definidos, a saber: unha nación branca, protestante e de lingua inglesa, como se pode comprobar, por exemplo, na serodia incorporación dalgúns estados do sur e na manipulación das fronteiras da Florida para garantir unha maioría de poboación anglosaxoa. Por outra banda, como Élise Marienstras demostrou, paralelamente á concepción das institucións federais como substituto da comunidade nacional, existe un proxecto de nación cultural a partir da introdución de temas tales como o da «nación civilizada» fronte aos «salvaxes» (decretando ab initio a expulsión dos indios da nación americana), a mitificación da cultura anglosaxoa como a única idónea para as tarefas do novo Estado, o carácter identitario nacional da relixión e a fusión de relixión (militantemente protestante, como amosan as leis anticatólicas de varios estados) e civismo (configurando como trazo cívico a pertenza a seitas ou Igrexas protestantes) (Marienstras 1976, 1988). A. Marx demostrou, así, a centralidade da exclusión fundacional dos afroamericanos da nación: a pluralidade e o conflito das múltiples identidades brancas derivadas da inmigración europea foron suturadas e unificadas como nación branca fronte ao «outro» inte- 
rior de raza negra (Marx 1988). Fronte ao mito do melting pot, Rogers M. Smith, nunha investigación decisiva, mostrou como se introducirían progresivamente restricións raciais desde 1882, se establecerían cotas raciais en 1924 e a política de «defensa étnica», desde a década de 1830 á de 1920, sentaría as bases do criterio de exclusión e asimilación mediante a Anglo-conformity. Outras investigacións puxeron de manifesto a dimensión étnica do nacionalismo americano, a delimitación dos true Americans que, ao fío da Primeira Guerra Mundial, artellaría nun mesmo discurso compoñentes racistas, cristiano-fundamentalistas e militaristas (O’Leary 1999). Elementos étnico-culturais que adquirirían tal peso en diferentes conxunturas, nas políticas e prácticas de segregación ata a década dos sesenta do século xx que, de se aceptar retoricamente a dicotomía aquí cuestionada, para algúns especialistas sería máis exacto cualificar o nacionalismo dos EUA como nacionalismo exemplar de tipo étnico (Kaufmann 1999, 2000).

En segundo lugar, o estereotipo resulta igualmente simplificador e insostible no que atinxe á natureza exclusivamente étnica do nacionalismo «oriental». Do mesmo xeito que no tipo occidental existen anomalías xeográficas de peso — sen ir máis lonxe: o caso español-, tampouco un suposto nacionalismo oriental etnicista fai xustiza aos casos checo ou húngaro. Ou mesmo o alemán, tomado en toda a súa traxectoria. En efecto, de especial interese resulta a desvirtualización do caso alemán, pois, como xa vimos, o dualismo política/cultura superponse sobre o eixe Francia/Alemaña e refórzase sobre o de Ilustración/Romanticismo.

Segundo xa se observou no primeiro apartado, os estudos contemporáneos sobre o romanticismo filosófico e político abandonaron a caricatura que desde Heine e Ruge, elaborada sobre a innegable evolución última, conservadora ou mesmo reaccionaria, dalgúns dos románticos máis destacados, o postulaba como a negación, o totalmente outro da Ilustración. Neste senso, a obra de Beiser mostrou de xeito concluínte os vencellos co republicanismo, ata datas moi serodias, dos principais románticos alemáns, como Novalis, Schleiermacher ou Hölderlin, a súa matizada crítica á Ilustración, o seu comunitarismo democrático, o sentido moi preciso da contraposición organicismo/mecanicismo, o carácter político e non meramente estético do movemento (Beiser 1992). Michael Löwy subliñou, pola súa banda, a índole de crítica moderna, non pasadista, da modernidade nos románticos alemáns e a presenza dun romanticismo reformista ou revolucionario de Heine a Moses Hess, de Heine a Gustav Landauer (Löwy e Sayre 1992). 
Finalmente, Robert Richards, nun monumental traballo, desmontou a visión do pensamento romántico e a súa versión da Naturphilosophie como anticientífica, antiempírica e mística, e postulou a súa continuidade no pensamento de Darwin (Richards 2002).

Pola súa banda, a historiografía contemporánea someteu a crítica definitiva o arquetipo do excepcionalismo alemán —o Sonderweg-, a esaxeración de ler a historia de Alemaña desde o nazismo, reducindo a meros prolegómenos deste a complexa evolución anterior e contrapondo, fronte a unha suposta apoteose liberal das nacións occidentais, un camiño inequívoco e predestinado ao nacionalismo étnico e autoritario (Blackbourn e Eley 1984, Brubaker 1992). John Breuilly iluminou un panorama ben diferente e moito menos unívoco. Así, por exemplo, na Asemblea parlamentaria de Frankfurt de 1848 predominaba unha perspectiva liberal centrada no debate habido arredor da Constitución e os dereitos civís e políticos, ata o extremo de que a idea de nacionalidade do Estado se formulaba en termos de cidadanía, recoñecéndose a presenza de linguas minoritarias, e todo isto sen referencia a criterios étnicos. De feito, o novo Estado ao que se aspiraba non era considerado de ningún xeito como a expresión dunha identidade cultural subxacente, senón como un proxecto político (Breuilly 1993: 96). O propio Brubaker, que defende un uso matizado da distinción entre as concepcións alemá e francesa de nacionalidade, entende que o fracaso de Prusia na asimilación dos polacos se diferenza en grao, que non en calidade, do fracaso da asimilación francesa de bretóns, vascos, corsos ou alsacianos, motivada polo efecto fronteira co mundo eslavo (Brubaker 1992).

Poderiamos multiplicar os exemplos, mais só pretendemos deixar constancia de que unha leve ollada histórica mostra de xeito patente que os nacionalismos cívicos non son tan escrupulosamente "cívicos», e que os nacionalismos "étnicos» resultan en ocasións máis cívicos do que se lles supón. A bibliografía máis recente insiste en que toda nación é unha articulación complexa de elementos culturais e políticos, e moi especialmente en que esta articulación muda ao longo do tempo segundo específicas conxunturas e correlacións de forzas. Isto, no entanto, non supón, como algúns autores críticos coa dicotomía étnico/cívico sinalaron, que o proceso sexa unívoco e evolutivo desde unha inicial fase étnica a outra de madurez cívica. Na obra de Anthony Marx ou Taras Kuzio formúlase de modo diverso esta hipótese. $\mathrm{O}$ último, por exemplo, postula unha fase étnica que se mantén ata 
a década dos sesenta en Occidente (EUA) e se prolonga no leste ata os noventa, despois da caída do muro (Breton 2002, Marx 2003, Kuzio 2002). No entanto, o carácter evolutivo e relacional de cada nacionalismo en concreto, por mor de conxunturas internas e externas, da súa propia estrutura de oportunidade política e específicos formatos de mobilización e discurso (Máiz 2012), impide establecer unha síntese definitiva, unha sutura no proceso de construción nacional nun momento dado, conxelándoo nunha fase ora étnica, ora cívica. Así, os nacionalismos dos Estados nados da ruptura da ex-Iugoslavia e a ex-URss xeraron variedades ben diferentes de nacionalismos, unhas veces «nacionalizadores», outras democráticos na súa evolución (Brubaker 1996); e os nacionalismos occidentais experimentaron unha involución xenofóbica e racista, cando non estritamente fundamentalista (Silverman 1992).

Por outra banda, os estudos empíricos comparativos que ata agora se levan feito, empregando diferentes variables independentes, mostran 1) a natureza étnico-cultural e política á vez dos diferentes nacionalismos europeos (Krejčí e Velímský 1996) e 2) a forte presenza, nas nacións occidentais a mediados dos anos noventa, das concepcións fortemente culturais da nación e o apoio máis ben feble ao multiculturalismo (Shulman 2002).

Ora ben, os problemas fundamentais da dicotomía étnico/cívico non son de orde empírica, con ser estes moi importantes, senón de orde propiamente teórica. En efecto, escindindo a dimensión étnico-cultural da dimensión cívico-política e orixinando sobre cada unha delas un tipo ou modelo de nacionalismo, oclúese a posibilidade de dar conta cabal da nación — quer Estado-nación, quer «nación sen Estado»- como un proceso de articulación complexa de elementos políticos e culturais en contextos sociais específicos. Por iso non podemos aceptar, como se propuxo recentemente, salvar a dicotomía por mor do seu pretendido valor heurístico, se ben non como descrición empírica, senón como «tipo ideal» weberiano, que permitiría analizar amálgamas de compoñentes cívicas e étnicas en cada nacionalismo empírico (Zubrzycki 2002). Porque non hai, en rigor, dous tipos ideais de nación, un étnico e outro cívico, senón que o tipo ideal, se así o formulamos, do fenómeno nacionalista se configura arredor, precisamente, da articulación inextricable de elementos étnicos e cívicos, que en cada caso se concretan en sínteses político-ideolóxicas moi diferentes. Se mantemos o valor teórico da distinción, 1) bloquéase a posibilidade de dar conta da nación como 
un proceso político aberto e continxente de construción, que evoluciona de xeito desigual no tempo, a teor de circunstancias internas e externas, e polo tanto non pode ser fixado dunha vez e para sempre como cívico ou como político; 2) impide dar conta do pluralismo de formulacións, de proxectos nacionais e de loita pola hexemonía que se libra no interior de cada nación, e que supoñen outras tantas amálgamas de entre as moitas (mais non infinitas, posto que limitadas polas precondicións étnico-culturais, xeográficas e institucionais dispoñibles) posibles, e 3) se interpretan mal a mobilización, o discurso e a cultura nacionalistas como a mera expresión dunha nación dada, desconsiderando a súa natureza de factores fundamentais da construción nacional. Pois o nacionalismo non expresa ou exterioriza unha nación que se remonta á noite dos tempos, senón que contribúe decisivamente á súa recreación contemporánea, xa que selecciona, filtra e reformula os materiais dados (discursivos, estratéxicos, institucionais etc.), vencellando demandas, valores, mitos e símbolos con intereses de determinados grupos sociais.

Por iso, máis ca dous mundos á parte, as dimensións capitais da nación situaríanse ao longo dun continuum étnico-cívico. Cada nacionalismo concreto, en cada conxuntura específica, desprazaríase sobre o mencionado contínuum, nun constante proceso de rearticulación de varios dos seus elementos, con ritmos e tempos cambiantes, competindo pola hexemonía, pola dirección intelectual e moral da nación, con outras sínteses ben de elementos diferentes ou ben reelaboracións dos elementos mesmos. E sempre baixo a inercia da herdanza das formulacións pasadas, do peso (por veces coma unha lousa sobre as costas das xeracións presentes) dos mitos, narrativas e símbolos recibidos da propia tradición nacional.

Finalmente, debemos engadir algunha breve consideración de carácter normativo. Pois, formulada como se dixo, desde a posición do patriotismo cívico, a distinción étnico/cívico posúe non só os moi serios problemas empíricos e teórico-positivos xa vistos no apartado anterior, senón, así mesmo, moi notorios déficits teórico-normativos. En efecto, dando por resolta a fixación do demos mediante o recurso ao «esquecemento» da exclusión relixiosa e a violencia fundacional á que aludía Renan, e con isto a preexistencia coextensiva e autoevidente dun só pobo ou nación en cada Estado, a célebre dicotomía non é senón a outra cara da negación do carácter nacionalista ao patriotismo (cívico) de Estado. Nace así a 
ecuación oculta do Estado-nación, a saber: un Estado = unha nación = unha cultu$\mathrm{ra}=$ unha lingua $=$ unha historia. Como vimos, porén, o postulado da pretendida neutralidade estatal en materia cultural, tendo en conta que todo Estado-nación foi e é simultaneamente étnico e cívico, exclúe da avaliación normativa dous feitos fundamentais: 1) a imposición da cultura, da lingua e da narrativa histórica e mítico-simbólica da comunidade maioritaria sobre as minorías, abocadas á aculturación e á asimilación como contrapartida da adquisición da cidadanía igual, e 2) a conseguinte desigualdade estrutural, xeradora dunha cidadanía de segunda, que deste contrato de adhesión asimilacionista se deriva para os grupos e minorías nacionais internos, alí onde no canto dun demos existen unha pluralidade de demoi.

A falacia «é/debe» que se oculta no trade-off entre cidadanía libre e igual (patriotismo) e asimilación masiva na cultura e a lingua maioritarias (nacionalismo) resulta así evidente: do feito empírico da construción histórica dos estados nacionais derívase a irrelevancia ético-política da multinacionalidade. O problema é que esta falacia fundacional impide a análise e a crítica normativa destes procesos de construción nacional, isto é, a súa xustificabilidade en termos de esixencias da teoría da democracia, a saber: liberdade, igualdade, tolerancia, pluralismo, participación, deliberación, inclusión das minorías. E isto tanto nos nacionalismos de Estado como nos nacionalismos das nacións sen Estado, os cales, ao compartiren a argumentación subxacente no Estado-nación, adoptan especularmente, se ben invertida, parecida lóxica: unha historia nacional $=$ unha lingua $=$ unha cultura $=$ unha nación = un Estado independente.

Unha teoría normativa do nacionalismo democrático ha incorporar, porén, asuncións ben diferentes, que coinciden en boa medida coas xa examinadas no apartado anterior sobre o multiculturalismo: 1) o presuposto de que todo nacionalismo "cívico» ou patriotismo comporta elementos étnicos e culturais; do mesmo xeito que todo nacionalismo étnico-cultural debe responder en termos democráticos ás cuestións chaves da cidadanía: liberdade, pluralismo e inclusión; 2) que non adoitan corresponderse as fronteiras políticas e as culturais e que ningún territorio é monocultural, nin, xa que logo, titularidade ou patrimonio dunha soa cultura; 3) que a nación non é unha comunidade dada, inmutable, senón o resultado continxente dun proceso político de construción nacional e, polo tanto, constitúe un proxecto aberto; 4) que cada particular combinatoria 
de elementos políticos e étnicos proposta por cada nacionalismo é sempre o resultado dunha hexemonía entre as varias posibles e, por definición, contestable e contestada, polo que debe ser sometida a escrutinio ou avaliación normativa; 5) mais á vez resulta preciso garantir democraticamente as condicións de contexto para a deliberación, a participación e a inclusión de maiorías, minorías e individuos singulares na conversa a múltiples voces que constitúe cada nación.

Neste sentido, a evolución do debate sobre o nacionalismo democrático, o coñecido en teoría política como liberal nationalism debate, seguiu un curso moi claro: o abandono da dicotomía nacionalismo étnico-cultural/nacionalismo cívico (patriotismo). Nun primeiro momento, prodúcese unha radical depuración das compoñentes diacríticas máis organicistas do núcleo duro da etnicidade («raza», Volksgeist, relixión etc.) e promóvese unha rearticulación culturalista da idea de nación. Así, factores como a lingua, a historia, a cultura, as institucións, pasan a integrar o núcleo duro do concepto de nación, flexibilizando dun xeito importante o naturalismo e o determinismo dos factores «obxectivos» que cualifican a presenza dunha nación. Esta versión culturalista do nacionalismo permite algo fundamental, un achegamento ás demandas democráticas, á conciliación de demandas de maiorías e minorías, á posta en marcha de mecanismos de inclusión non coactivos etc. Ora ben, nun segundo momento do debate obsérvase que este xiro culturalista do concepto de nación, se ben decisivo, con respecto ao tradicional modelo organicista, posúe límites importantes: ante todo segue a ser un modelo monista, onde unha nación $=$ unha lingua $=$ unha cultura. Este monismo impide a completa politización democrática do concepto de nación, que require de modo ineludible — como xa vimos no debate do multiculturalismo- a introdución do pluralismo: non só ideolóxico, senón tamén cultural e lingüístico, no interior de cada nación. A necesidade, en definitiva, de dar un paso máis aló do nacionalismo cultural, retendo as súas achegas, para realzar unha nova síntese pluralista ou, en suma, un concepto pluralista de nación, que abandone a asunción monista — un territorio, unha nación, unha lingua — para se abrir a fórmulas de negociación, tolerancia e igual respecto entre maiorías e minorías lingüísticas, culturais e relixiosas, mediante o que deu en se chamar reasonable accommodations (Máiz 2012). 


\section{O CONCEPTO EMERXENTE DA CULTURA COMO PRÁCTICA SE- MIÓTICA NA CIENCIA POLÍTICA}

Pois ben, en importante sintonía co visto anteriormente na teoría política do multiculturalismo e o nacionalismo democrático, na ciencia política contemporánea gañou peso, paralelamente ao desenvolvemento da liña tradicional de investigación sobre a cultura política (Norris 1999, Dalton 2002, Wiarda 2002), un programa de investigación alternativo no que a cultura se estuda como un sistema de símbolos que prové de sentido político a vida colectiva dos cidadáns. En ocasións esta nova perspectiva resulta debedora explicitamente da teoría posmoderna (Wedeen 2002, Ross 2009); noutras, das achegas interpretativas da antropoloxía de Cohen ou Geertz (Laitin 1986). Mesmo no seo do paradigma tradicional, na obra de Inglehart, que —a diferenza de Almond e Verba, preocupados pola persistencia das culturas políticas no curso do tempo- se centrou desde un comezo na mudanza política e cultural, aparecerá un recońecemento explícito do carácter inherentemente normativo da democracia e dos «valores de autoexpresión» que a sustentan (Inglehart 2005).

Non debe esquecerse que para a moderna bioloxía e psicoloxía evolucionistas (e a ciencia cultural que se basea nelas) a correcta secuencia explicativa, a diferenza do behaviorismo, é como segue: empatía-instinto social-comunidade-linguaxe e culturavalores compartidos-acción individual. Como sinalaron Edward Wilson ou Mark Pagel: a cultura constitúe un mecanismo fundamental para a creación e a supervivencia dos grupos sociais (Wilson 2012: 281; Pagel 2012: 75). A cultura representa un mecanismo chave de formación grupal mediante as redes de significación, que producen meaningfulness, isto é, semiose que se constrúe en tres dimensión simultáneas: identidade, sociabilidade e sentido, xerando «strong reciprocity» que fai dos seres humanos unha excepcionalmente «cooperative species» (Bowles e Gintis 2011). Así, a identidade individual é un resultado da sociabilidade, non o seu punto de partida, e a conduta xorde da comunicación intersubxectiva no seo dun grupo cuxa idea de como se debe actuar depende de desexos compartidos e da aprobación dos outros membros. En suma: «culture sets the rules for individual action [...]. '[C]ulture makes us' rather than the other way round» (Hartley e Potts 2014: 4).

$\mathrm{Na}$ ciencia política máis recente, baixo os varios impulsos xa citados, podemos subliñar polo menos tres dimensións dun novo concepto de cultura emerxente. 
Dimensións que resultan especialmente pertinentes para dotar de base explicativa rigorosa a teoría política normativa, que ten que lidar coa dimensión cultural. a. - A cultura como conxunto de prácticas de dotación de significado. Nesta perspectiva, a cultura resulta decisiva para a análise da política porque dota de sentido as accións e as identidades dos actores organizando os seus significados e fornecendo un horizonte normativo para a súa vida, os seus intereses, as súas institucións, as súas estratexias (Sewell 1999). A análise da produción política do sentido require a investigación sistemática das conexións entre as prácticas dos actores políticos (participación, identificación, traballo etc.) e os sistemas de significación que os conforman (símbolos, mitos, linguaxe etc.). Deste xeito, a concepción da cultura como "práctica cultural», "practices embedded in traditions» (Bevir e Rhodes 2010), como práctica semiótica, posúe implicacións fundamentais (Wedeen 2002, Norton 2004, Chabal e Daloz 2006): a) investiga o que a linguaxe, os mitos e os símbolos «causan» en canto "webs of significance», isto é, como se insiren, en calidade de variables independentes, en determinadas accións e producen efectos políticos empiricamente observables; b) atende, así mesmo, á súa condición de «efectos» semióticos, en calidade de variable dependente, das estruturas de dominación, os arranxos institucionais e o conflito entre intereses estratéxicos, e d) dá conta, en fin, dun conxunto de fenómenos políticos que os programas tradicionais de investigación da «cultura política» desatendían: a explicación de por que e como os actores dotan de sentido, histórica e conflitivamente, determinadas accións ou institucións políticas. De especial interese resulta a capacidade deste enfoque para abordar os procesos de xénese de autoevidencias, naturalización e autoridade en ámbitos como relixión, identidade, lexitimidade democrática etc. Isto é, estúdase a produción da mínima intelixibilidade imprescindible para un grupo se recoñecer en determinados signos, os cales, pola súa vez, se poñen de manifesto a través de prácticas diversas de significación. Ora ben, tradicións, símbolos, imaxes, identidades e textos deveñen, nesta perspectiva, signos cuxo significado está sempre provisionalmente fixado, resulta precario e cambiante no tempo, obxecto de relacións de poder, de contestación e conflito. Así, o que a primeira vista pode parecer natural, coherente, cristalizado como unha totalidade acabada e discreta, resulta sempre produto continxente de procesos de mudanza e loitas entre interpretacións opostas. Por esta razón deben ser investigadas empiricamente en cada caso concreto (Wedeen 1999). 
b.- A cultura como recurso para a mobilización e a organización política. A cultura fornece esquemas e marcos de intelixibilidade política e por isto constitúe unha decisiva fonte de recursos organizativos e para a acción (Ross 2007, 2009). A obra seminal de Edelman Politics as Symbolic Action (Edelman 1971), de extraordinario interese neste sentido, resultou moi desatendida ata datas posteriores á eclosión dos estudos sobre os movementos sociais. En efecto, esta dimensión cultural situarase no fulcro dos novos programas de investigación xurdidos con posterioridade aos paradigmas iniciais do «proceso político» e a «mobilización de recursos» (McAdam, Tarrow e Tilly 2009) e desenvolvidos polos modelos construtivistas, a partir da obra pioneira de Alberto Melucci, ao chamaren a atención sobre a condición dos novos movementos sociais de portadores de novos códigos culturais. A partir dos anos noventa (McAdam, McCarthy e Zald 1996), a dimensión cultural, quer a través dos procesos de encadramento (framing) da mobilización, quer das tradicións culturais de mobilización, construíu unha dimensión fundamental da axenda de investigación da política de protesta. O horizonte clásico, debedor da tradición estruturalista, deu paso a unha análise atenta non só á interacción estratéxica entre os actores, senón tamén ás distintas formas de conciencia política e á cultura historicamente acumulada por movementos e organizacións (Máiz 2011). A hipótese de que o contexto histórico e cultural en que discorre a mobilización afecta dun xeito significativo aos actores, ás súas traxectorias, estratexias e concatenacións de mecanismos causais constituirá un novo punto de partida. Encadramento e interpretación representan, desde aquela, moito máis ca unha outra variable explicativa, para se integraren nun máis amplo contexto interpretativo, que abrangue desde a percepción das oportunidades políticas aos procesos de construción de identidades (McAdam, Tarrow e Tilly 2001). Así, os repertorios de acción colectiva constitúen un conxunto de costumes, hábitos e interpretacións que resultan compartidos, transmitidos e aprendidos; en suma, auténticas «creacións» (Tilly). En definitiva, as culturas e os procesos interpretativos que as integran e difunden non son considerados como meros condicionantes externos da mobilización política, senón que se analizan como factores implicados nas interaccións mesmas entre os actores en conflito.

c.- A cultura como conexión entre as identidades individuais e colectivas. A última dimensión que queremos destacar é a reformulación dos programas de investigación da elección racional para dar cabida, en complexa articulación cos seus supostos de 
individualismo metodolóxico, á dimensión cultural intersubxectiva, logo de seren consideradas estas por longo tempo «mutuamente excluíntes e antagonistas» (Bates, Figueiredo e Weingast 1998). Nesta perspectiva, a cultura considérase como máis ca un recurso facilitador da acción colectiva, para se analizar como un conxunto de crenzas, normas e visións do mundo. Así, a cultura (signos, símbolos, linguaxe) é relevante para os individuos en canto que os provén de sentido colectivo na súa vida mediante os valores profundamente arraigados no grupo cultural (Laitin 1986). A recuperación da fonda dimensión intersubxectiva da análise, perdida en moitos estudos tributarios do individualismo metodolóxico, vehicúlase a través da escolla cultural estratéxica dos autores; isto é, de decisións baseadas nos intereses propios e no curso de acción previsto por parte dos demais (Laitin 1998). Nesta perspectiva ábrese unha liña de investigación - a cultura como equilibrio dinámico- que ten como obxectivo analizar os procesos mediante os cales os membros dos grupos culturais - i. e., os que comparten un conxunto de prácticas simbólicas (relixión, lingua, arte, rituais)—, mediante unha urda de símbolos compartidos, prácticas rituais e unha densa interacción, condicionan o seu comportamento mediante crenzas culturais - i. e., de sentido común compartido- sobre o comportamento esperable por parte dos outros membros do grupo (Laitin e Weingast 2006). Toda cultura grupal, en principio, se atopa nunha condición de equilibrio, isto é, posúe unha estrutura de autorreforzo que incentiva a pertenza a ela (positiva e negativamente), excepto no caso de inconsistencia radical das crenzas coa realidade social dos actores. Así, por unha banda a coordinación estratéxica volve a cultura estable, se ben con capacidade de mudanza (equilibrio dinámico); pola outra, os símbolos compartidos constitúen o fundamento de visións do mundo comúns que provén os membros dun grupo cultural de algo moi valioso e substantivo, non meramente instrumental: un mundo de sentido compartido. E, fronte á reticencia a investigar as identidades colectivas, este programa de investigación permite considerar as nacións como poboacións dotadas dun conxunto coordinado de crenzas sobre a súa identidade cultural con pretensións ao dispor dun Estado propio (Laitin 2007). Deste xeito, a cultura devén un factor fundamental da identidade, sen resultar por iso nin ubicua nin holística, nin cristalizada nin allea ao conflito interno, e pode ser analizada empiricamente como un proceso continxente e estratéxico de construción política.

En conclusión: as achegas destes programas construtivistas e relacionais de investigación non só, como tratamos de mostrar, sintonizan coas elaboracións da teoría política máis recente sobre nacionalismo e multiculturalismo. Trátase 
de moito máis ca iso: co seu fincapé, por unha banda — fronte ás perspectivas instrumentalistas-, no capital relevo político da dimensión cultural como provedora de significado compartido para os grupos e as comunidades, e, pola outra —fronte ás perspectivas primordialistas_, no carácter continxente, construído e internamente conflitivo de toda identidade cultural, resultan de indubidable interese, de feito imprescindibles, para o debate teórico normativo sobre o multiculturalismo, o nacionalismo e a democracia. O prezo de non incorporar as súas achegas sería moi alto: limitarse a ilustrar a reflexión teórica con meros exemplos impresionistas ad hoc; prescindir dunha sólida base explicativa e comparada para os referentes empíricos da argumentación; e seguir asumindo un concepto prepolítico, esencialista e holista de cultura, nación ou grupo étnico abandonado hai tempo, por insostible, na investigación máis solvente da ciencia social contemporánea. 


\section{REFERENCIAS BIBLIOGRÁFICAS}

Almond, Gabriel A. / Sidney Verba (1963): The Civic Culture: Political Attitudes and Democracy in Five Nations, Princeton, Princeton University Press.

Almond, Gabriel A. / G. Bingham Powell Jr. (1966): Comparative Politics: A Developmental Approach, Boston, Little Brown.

Aвrams, Meyer Howard (1971): Romanticism: Tradition and Revolution, Nova York, Norton.

Barry, Brian (2002): Culture and Equality: An Egalitarian Critique of Multiculturalism, Cambridge, Polity.

Bates, Robert H. / Rui J. P. de Figueiredo / Barry R. Weingast (1998): «The Politics of Interpretation:

Rationality, Culture, and Transition", Politics and Society, 26:4, 603-642.

Bauman, Zygmunt (1992): Intimations of Postmodernity, Londres, Routledge.

Bauman, Zygmunt (1993): Postmodern Ethics, Oxford, Blackwell.

Bauman, Zygmunt (1995): Life in Fragments: Essays in Postmodern Morality, Oxford, Blackwell.

BeIner, Ronald (ed.) (1999): Theorizing Nationalism, Albany, State University of New York Press.

Beiner, Ronald / Wayne Norman (2001): Canadian Political Philosophy, Oxford, Oxford University Press.

Beiser, Frederick C. (1987): The Fate of Reason: German Philosophy from Kant to Fichte, Cambridge, Harvard University Press.

BeIser, Frederick C. (1992): Enlightenment, Revolution, and Romanticism: The Genesis of Modern German Political Thought, 1790-1800, Cambridge, Harvard University Press.

Benhabib, Seyla (2002): The Claims of Culture: Equality and Diversity in the Global Era, Princeton, Princeton University Press.

BerLin, Isaiah (1999): The Roots of Romanticism, Princeton, Princeton University Press.

Best, Steven / Douglas Kellner (1997): The Postmodern Turn, Nova York, Guilford.

Bevir, Mark / R. A. W. Rhodes (2010): The State as Cultural Practice, Oxford, Oxford University Press.

Blackbourn, David / Geoff Eley (1984): The Peculiarities of German History: Bourgeois Society and Politics in Nineteenth-Century Germany, Oxford, Oxford University Press.

Bowles, Samuel / Herbert Gintis (2011): A Cooperative Species: Human Reciprocity and Its Evolution, Princeton, Princeton University Press.

Breton, Raymond (1988): «From Ethnic to Civic Nationalism: English Canada and Quebec», Ethnic and Racial Studies, 11:1, 85-102.

Breuilly, John (1996): Nationalism and the State, Manchester, Manchester University Press.

Brubaker, Rogers (1992): Citizenship and Nationhood in France and Germany, Cambridge, MA, Harvard University Press.

Brubaker, Rogers (1996): Reframing Nationalism, Cambridge, Cambridge University Press.

Brubaker, Rogers (2004): Ethnicity without Groups, Cambridge, Harvard University Press.

Caney, Simon (2002): «Equal Treatment, Exceptions and Cultural Diversity», en Paul Kelly (ed.), Multiculturalism Reconsidered: Culture and Equality and Its Critics, Cambridge, Polity, 81-101.

Carens, Joseph H. (2000): Culture, Citizenship, and Community: A Contextual Exploration of Justice as Evenhandedness, Oxford, Oxford University Press.

Chabal, Patrick / Jean-Pascal Daloz (2006): Culture Troubles: Politics and the Interpretation of Meaning, Chicago, University of Chicago Press. 
ChaI, Leon (2006): Romantic Theory: Forms of Reflexivity in the Revolutionary Era, Baltimore, Johns Hopkins.

Chandra, Kanchan (2012): Constructivist Theories of Ethnic Politics, Oxford, Oxford University Press.

Clifford, James (1998): The Predicament of Culture: Twentieth-Century Ethnography, Literature and Art, Cambridge, Harvard University Press.

Clifford, James / George E. Marcus (1986): Writing Culture: The Poetics and Politics of Ethnography, Berkeley, University of California Press.

Dalton, Russell J. (2002): Citizen Politics, Chatham, Chatham House.

Droz, Jacques (1966): Le Romantisme allemand et l'État: résistance et collaboration dans l'Allemagne napoléonienne, París, Payot.

EAgLeton, Terry (2000): The Idea of Culture, Londres, Blackwell.

Edelman, Murray (1971): Politics as Symbolic Action: Mass Arousal and Quiescence, Nova York, Markham.

Finkielkraut, Alain (1987): La Défaite de la pensée, París, Gallimard.

Galston, William (1991): Liberal Purposes: Goods, Virtues, and Diversity in the Liberal State, Nova York, Cambridge University Press.

Geertz, Clifford (1973): The Interpretation of Cultures, Nova York, Basic Books.

Geertz, Clifford (2000): Available Light: Anthropological Reflections on Philosophical Topics, Princeton, Princeton University Press.

Giddens, Anthony (1991): Modernity and Self-identity: Self and Society in the Late Modern Age, Cambridge, Polity.

Glazer, Nathan (1983): Ethnic Dilemmas, 1964-1982, Cambridge, Harvard University Press.

Glazer, Nathan (1997): We Are All Multiculturalists Now, Cambridge, Harvard University Press.

Hale, H. E. (2008): The Foundations of Ethnic Politics, Nova York, Cambridge University Press.

Hardt, Michael / Antonio Negri (2000): Empire, Cambridge, Harvard University Press.

Hardt, Michael / Antonio Negri (2004): Multitude: War and Democracy in the Age of Empire, Londres, Penguin.

Hardt, Michael / Antonio Negri (2009): Commonwealth, Cambridge, Harvard University Press.

Hartley, John / Jason Potтs (2014): Cultural Science: A Natural History of Stories, Demes, Knowledge and Innovation, Londres, Bloomsbury.

Huntington, Samuel P. (1996): The Clash of Civilizations and the Remaking of World Order, Nova York, Simons and Schuster.

Huntington, Samuel P. (2004): Who Are We?: The Challenges to America's National Identity, Nova York, Free Press.

Inglehart, Ronald (1990): Culture Shift in Advanced Industrial Society, Princeton, Princeton University Press.

Inglehart, Ronald (1997): Modernization and Postmodernization: Cultural, Economic and Political Change in 43 Societies, Princeton, Princeton University Press.

Inglehart, Ronald / Christian Welzel (2005): Modernization, Cultural Change, and Democracy: The Human Development Sequence, Nova York, Cambridge University Press.

Inglehart, Ronald / Pippa Norris (2018): Cultural Backlash, Nova York, Cambridge University Press Jameson, Fredric (1991): Postmodernism or, The Cultural Logic of Late Capitalism, Londres, Verso.

Kaufmann, Eric (1999): «American Exceptionalism Reconsidered: Anglo-Saxon Ethnogenesis in the "Universal" Nation, 1776-1850», Journal of American Studies, 33:3, 437-458. 
Kaufmann, Eric (2000): «Ethnic or Civic Nation?: Theorizing the American Case», Canadian Review of Studies in Nationalism, XXvII:1-2, 133-155.

Kelly, Paul (ed.) (2002): Multiculturalism Reconsidered: Culture and Equality and Its Critics, Cambridge, Polity.

King, Gary / Robert O. Keohane / Sidney Verba (1994): Designing Social Inquiry: Scientific Inference in Qualitative Research, Princeton, Princeton University Press.

KrejČí, Jaroslav / Vitězslav Velímský (1996): «Ethnic and Political Nations in Europe», en John Hutchinson, Anthony D. Smith (eds.), Ethnicity, Oxford, Oxford University Press.

Kuzıo, Taras (2002): «The Myth of the Civic State», Ethnic and Racial Studies, 25:1, 20-39.

Kyмlicка, Will (1995): Multicultural Citizenship: A Liberal Theory of Minority Rights, Oxford, Oxford University Press.

Kyмlicка, Will (2001): Politics in the Vernacular: Nationalism, Multiculturalism, and Citizenship, Oxford, Oxford University Press.

Kymlicka, Will / Wayne Norman (eds.) (2000): Citizenship in Diverse Societies, Oxford, Oxford University Press. Laborde, Cécile (2008): Critical Republicanism: The Hijab Controversy and Political Philosophy, Oxford, Oxford University Press.

Laden, Anthony Simon / David Owen (eds.) (2007): Multiculturalism and Political Theory, Cambridge, Cambridge University Press.

LAFOREST, Guy (1992): De la prudence : textes politiques, Québec, Bóreal.

LAForest, Guy (1995): De l'urgence : textes politiques, Québec, Boréal.

Laitin, David D. (1986): Hegemony and Culture: Politics and Change among the Yoruba, Chicago, University of Chicago Press.

Laitin, David D. (1998) Identity in Formation: The Russian-Speaking Populations in the New Abroad, Ithaca, NY, Cornell University Press.

Laitin, David D. (2007): Nations, States and Violence, Oxford, Oxford University Press.

Laitin, David D. / Barry R. Weingast (2006): «An Equilibrium Alternative to the Study of Culture», The Good Society, 15:1, 15-21.

Larmore, Charles E. (1996): The Romantic Legacy, NovaYork, Columbia University Press.

Levy, Jacob T. (2000): The Multiculturalism of Fear, Oxford, Oxford University Press.

Lipovetsky, G. (1986): La era del vacio, Barcelona, Anagrama.

LÖWY, Michael / Robert SAYRE (1992): Révolte et mélancolie: le romantisme à contre-courant de la modernité, París, Payot.

McAdam, Doug / John D. McCarthy / Mayer N. Zald (1996): Comparative Perspectives on Social Movements: Political Opportunities, Mobilizing Structures, and Cultural Framings, Cambridge, Cambridge University Press.

McAdam, Dough / Sidney Tarrow / Charles Tilly (2001): Dynamics of Contention, Cambridge, Cambridge University Press.

Márz, Ramón (2003): «Framing the Nation: Three Rival Versions of Political Nationalist Ideology», Journal of Political Ideologies, 8:3, 251-267.

Márz, Ramón (2011): «Las dos lógicas de la explicación en la obra de Charles Tilly: Estados y repertorios de protesta», en María Jesús Funes (ed.), A propósito de Tilly, Madrid, cis, 48-77.

Márz, Ramón (2012): The Inner Frontier: The Place of Nation in the Political Theory of Democracy and Federalism, Bruxelas, Peter Lang. 
Márz, Ramón (2018a): «Una cuerda sobre el abismo. Modernismo y Postmodernismo en Metrópolis (Fritz Lang) y Blade Runner (Ridley Scott)", en M. Alcántara / S. Mariani (coords.), La politica es de cine, Madrid, Centro de Estudios Políticos y Constitucionales.

Márz, Ramón (2018b): Nacionalismo y federalismo, Madrid, Siglo XXI.

Márz, Ramón / Ferrán Requejo (2005): Democracy, Nationalism and Multiculturalism, Londres, Routledge. Marienstras, Élise (1977): Les Mythes fondateurs de la nation américaine, París, Maspero.

Marienstras, Élise (1988): Nous le peuple: les origines du nationalisme américaine, París, Gallimard.

Marx, Anthony W. (1988): Making Race and Nation: A Comparison of South Africa, the United States, and Brazil, Cambridge, Cambridge University Press.

MarX, Anthony W. (2003): Faith in Nation: Exclusionary Origins of Nationalism, Nova York, Oxford University Press.

Miller, David (1995): On Nationality, Oxford, Oxford University Press.

Miller, David (2000): Citizenship and National Identity, Cambridge, Polity.

Miller, David (2002): «Liberalism, Equal Opportunities and Cultural Commitments», en Paul Kelly (ed.), Multiculturalism Reconsidered: Culture and Equality and Its Critics, Cambridge, Polity, 45-62.

Norman, Wayne (1995): «The Ideology of Shared Values: A Myopic Vision of Unity in the Multi-nation State», en Joseph H. Carens (ed.), Is Quebec Nationalism Just?: Perspectives from Anglophone Canada, Montreal e Kingston/Londres/Buffalo, MacGill-Queen's University Press.

Norris, Pippa (ed.) (1999): Critical Citizens: Global Support for Democratic Governance, Oxford, Oxford University Press.

Norton, Anne (2004): 95 Theses on Politics, Culture, and Method, New Haven, Yale University Press.

O'Leary, Cecilia Elizabeth (1999): To Die For: The Paradox of American Patriotism, Princeton, Princeton University Press.

Pagel, Mark D. (2012): Wired for Culture: The Natural History of Human Cooperation, Londres, Penguin. PAREKH, Bhikhu (2000): Rethinking Multiculturalism: Cultural Diversity and Political Theory, Londres, MacMillan. Poliakov, Léon (1971): Le Mythe aryen, París, Calmann-Lévy.

Pollock, Griselda (1996): Generations and Geographies in the Visual Arts, Londres, Routledge.

PolLock, Griselda (1999): Differencing the Canon: Feminist Desire and the Writing of Art's Histories, Londres, Routledge.

Przeworsky, Adam (1986): «Marxism and Rational Choice», Politics and Society, 14, 379-409.

Richards, Robert J. (2002): The Romantic Conception of Life: Science and Philosophy in the Age of Goethe, Chicago, University of Chicago Press.

Rorty, Richard (1989): Contingency, Irony, and Solidarity, Cambridge, Cambridge University Press.

Ross, Marc Howard (2007): Cultural Contestation in Ethnic Conflict, Cambridge, Cambridge University Press. Ross, Marc Howard (2009): «Culture in Comparative Political Analysis», en Mark Irving Lichbach, Alan S. Zuckerman (eds.), Comparative Politics: Rationality, Culture and Structure, Nova York, Cambridge University Press.

SAID, Edward W. (1978): Orientalism, Nova York, Vintage.

Schnapper, Dominique (1994): La Communauté des citoyens, París, Gallimard.

Sewell, William H., Jr. (1999): «The Concept(s) of Culture», en Victoria E. Bonnell, Lynn Hunt, Beyond the Cultural Turn: The Poetics and Politics of Ethnography, Berkeley, University of California Press, 35-61. 
Shulman, Stephen (2002): «Challenging the Civic/Ethnic and West/East Dichotomies in the Study of Nationalism», Comparative Political Studies, 35:5, 554-585.

Silverman, Maxim (1992): Deconstructing the Nation: Immigration, Racism and Citizenship in Modern France, Londres, Routledge.

SMith, Anthony D. (1986): The Ethnic Origins of Nations, Oxford, Blackwell.

Sмiтн, Anthony D. (1991): National Identity, Londres, Penguin.

Sмith, Anthony D. (1996): "Civic and Ethnic Nationalism Revisited», The ASEN Bulletin, 12, 9-14.

SMITH, Anthony D. (1999): Myths and Memories of the Nation, Oxford, Oxford University Press.

SмIтн, Anthony D. (2000): The Nation in History: Historiographical Debates about Ethnicity and Nationalism, Cambridge, Polity.

TAYlor, Charles (1989): Sources of the Self: The Making of the Modern Identity, Cambridge, Cambridge University Press.

TAYLOR, Charles (1992): «The Politics of Recognition», en Multiculturalism and "The Politics of Recognition", ed. Amy Gutmann, Princeton, Princeton University Press.

Tully, James (1995): Strange Multiplicity: Constitutionalism in an Age of Diversity, Cambridge, Cambridge University Press.

Tully, James (2002): «The Illiberal Liberal: Brian Barry's Polemical Attack on Multiculturalism», en Paul Kelly (ed.), Multiculturalism Reconsidered: Culture and Equality and Its Critics, Cambridge, Polity, 102$-113$.

Verba, Sidney / Norman H. Nie / Jae-on Kim (1978): Participation and Political Equality: A Seven-Nation Comparison, Cambridge, Cambridge University Press.

VIroli, Maurizio (1995): For Love of Country: An Essay on Patriotism and Nationalism, Oxford, Oxford University Press.

Walzer, Michael (1996): Thick and Thin: Moral Argument at Home and Abroad, Notre Dame, University of Notre Dame Press.

Walzer, Michael (2004): Politics and Passion: Toward a More Egalitarian Liberalism, New Haven, Yale University Press.

Weber, Eugen (1976): Peasants into Frenchmen: The Modernization of Rural France, 1870-1914, Stanford, Stanford University Press.

Weber, Eugen (1991): My France: Politics, Culture, Myth, Cambridge, MA, Harvard University Press.

Wedeen, Lisa (1999): Ambiguities of Domination: Politics, Rhetoric, and Symbols in Contemporary Syria, Chicago, University of Chicago Press.

Wedeen, Lisa (2002): «Conceptualizing Culture: Possibilities for Political Science», American Political Science Review, 96:4, 713-728.

Wedeen, Lisa (2008): Peripheral Visions: Publics, Power, and Performance in Yemen, Chicago, University of Chicago Press.

Wiarda, Howard J. (2002): New Directions in Comparative Politics, Boulder, Westview Press.

Willett, Cynthia (ed.) (1998): Theorizing Multiculturalism: A Guide to the Current Debate, Oxford, Blackwell.

Williams, Raymond (1963): Culture and Society: 1780-1950, Londres, Hardmonsworth.

Wilson, Edward O. (2012): La conquista social de la Tierra, Barcelona, Random House Mondadori. 
Young, Iris Marion (2000): «Self-Determination and Global Democracy: A Critique of Liberal Nationalism», en Ian Shapiro / Stephen Macedo (eds.), Designing Democratic Institutions, Nova York, New York University Press, 147-184.

ZubrZYCKI, Geneviève (2002): «The Classical Opposition Between Civic and Ethnic Models of Nationhood: Ideology, Empirical Reality and Social Scientific Analysis», Polish Sociological Review, 3, 275-295. 